\title{
Do individual investors consciously speculate on reversals? Evidence from leveraged warrant trading
}

\author{
Miklós Farkas* \\ University of Bristol
}

\author{
Kata Váradi \\ Corvinus University of Budapest
}

December 20, 2017

\begin{abstract}
Using proprietary data on bank-issued knock-out warrants, we find that individual investors, on aggregate, bet on price reversals. In a simple model we demonstrate that a mechanical channel due to market and product characteristics may account for investors' betting on reversals, even if investors' purchasing and selling decisions are independent of past returns. Our empirical results suggest that the mechanical channel can explain almost one half of the association between past returns and individual investors' order flow, while the rest can be attributed to the disposition effect, that is, investors' higher propensity to sell assets from their portfolios that have appreciated.
\end{abstract}

\section{Introduction}

The popularity of bank issued retail structured products increased significantly in the recent decade. In Germany, where these products are most popular, the total outstanding value of the exchange traded products (in Stuttgart and Frankfurt) was over $€ 68 \mathrm{bn}$ in March 2016地 The purpose of structured products is to liberate the retail investor by providing access to a wide range of derivative products, which was only available for institutional investors previously. As it is often argued by banks, individual investors have limited access to derivatives markets because they cannot afford the costs of maintaining a margin account. Therefore, banks designed structured products such that investors cannot lose more than the money they invest, which makes it very convenient for them.

Using proprietary data on bank-issued knock-out warrants written on the German DAX index allows us to track investors' aggregate position. We find that individual

${ }^{*}$ E-mail: miklos.farkas@bristol.ac.uk. This paper is a revised version of Chapter 3 of Miklos's PhD thesis at Central European University. We are grateful to Péter Kondor, Botond Kószegi and Adam Zawadowski for valuable guidance. Also, we would like to thank Zsolt Bihary, George Bulkley, Miklós Koren and Sergey Lychagin for comments and discussions as well as participants at the Hungarian Economic Society Meeting 2017 and the Seventh Annual Financial Market Liquidity Conference.

1 Deutsche Derivative Verband (2016)

${ }^{2}$ In order to put this number in perspective, consider the fact that the total market capitalization of the 30 largest German companies is in the range of $€ 1000 \mathrm{bn}$ at that time. Also, Célérier and Vallée (2017) show that the total amount of sold structured products (including non-exchange traded) since 2000 is over 2 trillion euros. 
investors bet on price reversals. The finding is consistent with the disposition effect, that is, investors' higher propensity to sell winners from their portfolios compared to selling losers. In particular, after positive returns of the DAX, investors are more likely to sell their call contracts, while after negative returns, they are more likely to sell their puts. In addition, we demonstrate in a simple model that a mechanical channel due to market and product characteristics may also account for investors' betting on reversals, even if investors' selling decision is independent of past returns. We start with the observation that a positive (negative) return on the underlying decreases (increases) the leverage of the available call warrant relative to the leverage of the available put warrant. In turn, if the leverage of available call is higher than the leverage of the put and investors allocate their funds randomly between taking long and short positions, then investors, on aggregate, end up having a long position. Our empirical results suggest that this mechanical effect can explain almost one half of the association between past returns and individual investors' order flow.

The market for knock-out warrants provides an attractive laboratory to analyze individual investor behavior for two reasons. First, only individual investors purchase these. Institutional investors have better alternatives, like standard options exchanges where counterparty risk is managed. ${ }^{3}$ Second, banks offer both call and put options for the underlying assets which makes it equally convenient for investors to take long and short positions. In particular, investors do not incur the typical costs of posting collateral to their broker when short selling an asset. Banks quote prices for their offered warrants through standard exchanges, allowing individuals to easily access these and also resell them to the issuing bank, should they wish to do so.

Knock-out warrants (also known as leverage/turbo certificates) are barrier options, that expire before their maturity date if the underlying's price reaches a prespecified barrier. Technically (based on their payoff functions), they are down-and-out barrier call options and up-and-out barrier put options. That is, the call (put) warrant gets knocked out and expires when the underlying reaches a lower (upper) bound or when they reach maturity without hitting their respective barrier. They are referred to as warrants because the issuing bank does not have to post a margin as collateral when selling these to investors (hence they carry the credit risk of the issuing bank). Since barrier options have some characteristics that resemble futures contracts, banks often advertise knock-out warrants as futures contracts and investors use these to carry out speculative bets. However, a distinctive feature of knock-out warrants is that their leverage sharply varies with the underlying's value. When the underlying appreciates the leverage of a call (put) warrant decreases (increases).

We have obtained transaction level data on warrants written on the German DAX index, a blue chip stock market index consisting of 30 major German firms. Our warrants are issued by a mid-sized European bank and were issued on a regional exchange. 4 For each transaction we can see a time stamp, the number of contracts exchanged, the price and, most importantly, the sign of the trade. Therefore, the classification into buy and sell volume in our data is exact. That is, we know whether investors are purchasing the warrants from the bank or reselling them to the bank for each trade. This allows us to track investors' aggregate position. The obvious limitation of the data is that we cannot link transactions to individuals 5

\footnotetext{
${ }^{3}$ Average value of a trade is below $€ 2000$ in our sample, which also suggests that institutional investors are not present.

${ }^{4}$ We have agreed not to name the bank who provided us the data.

${ }^{5}$ Since the warrants are traded through an exchange the issuing bank also has no information
} 
As a main result, we show that investors bet on price reversals. That is, investors tend to be net buyers of call contracts after contractions in the DAX and, symmetrically, net buyers of put contracts after increases in the DAX.

However, as we demonstrate in a simple model, due to product and market characteristics a mechanical channel could account for investors' aggregate behavior. In the model, investors individually randomize between speculating for increases and decreases in the DAX by buying the available call or put warrant, respectively. Importantly, investors who arrive to the exchange have a fixed sum to speculate with. Therefore, if the available call warrant happens to have higher leverage compared to the available put warrant, then - in expectation - arriving investors open a long position. We label the difference between the call's and put's leverage the leverage differential. Our insight is that the leverage differential perfectly correlates with past returns, introducing a mechanical correlation between past returns and investors' order flow.

Empirical results suggest that the mechanical channel is relevant. We bring our model to the data in a reduced form analysis by introducing the leverage differential as a control variable. Our estimates suggest that our proposed mechanical channel accounts for almost one half of the association between past returns and investors' order flow.

Investors speculate on price reversals mainly through their selling decisions, which is consistent with the disposition effect. That is, after a warrant appreciates, investors are more likely to become net sellers of the warrant. Since this pattern is detected for both call and put warrants, investors, on aggregate, bet on price reversals both after appreciations and depreciations of the DAX index. Additionally, we provide evidence indicating that relatively larger investors' purchasing decisions are not affected by past returns (except for the mechanical channel), while relatively smaller investors place bets on price reversals through their purchasing decisions, too.

Figures 1.3 give a graphical summary of our main findings. The difference between the number of call and put contracts investors hold is an accurate proxy for their aggregate exposure to the DAX index. It tells us how many (constant multiple of) euros investors' total portfolio appreciates if the DAX index increases by one unit. Figure 1 confirms that investors build up long positions during contractions in the underlying and short positions during increases in the underlying. That is, they speculate on reversals.

Figure 2 shows the available menu of call and put contracts represented by their barriers in our sample. Barriers below the DAX index represent call contracts and those above represent put contracts. Since the leverage of a given contract is inversely related to the distance between the barrier and the underlying, the leverage differential of available call and put contracts varies significantly. Finally, the leverage differential of the highest levered call and highest levered put is shown on Figure 3, together with investors' aggregate exposure. The correlation is remarkably strong, suggesting that the mechanical channel described above plays a crucial role in investors' positions.

\section{$1.1 \quad$ Related literature}

To the best of our knowledge this is the first paper to analyze individual investors' order flow in the market of knock-out warrants. Banks offer knock-out warrants that enable individual investors to carry out directional bets, both long and short, in a

about the investor's identity in a given transaction. 
convenient way. We show in a model that if investors allocate their funds randomly between long and short positions, the asymmetric leverage of offered products leads investors to speculate on price reversals through a mechanical channel. Our empirical results suggest that investors, in fact, bet on price reversals, even after accounting for this mechanical channel.

Our findings are in line with previous research suggesting that individuals are contrarians. Contrarian behavior is a label for investors betting on reversals: a negative correlation of past returns and investors' net purchases. One interpretation of contrarian behavior is that individuals provide liquidity to institutions who value immediacy. Kaniel et al. (2008) provide evidence from NYSE stocks which suggest that individuals provide liquidity and their behavior is rewarded with excess returns. Focusing on earnings announcements, Kaniel et al. (2012) show that individual investors' abnormal returns after earnings announcements can be decomposed into an information and a liquidity provision component. Their results indicate that both components contribute about equally to individuals' excess returns. Our different setting and our focus on the DAX index makes it unlikely that informed trading could take place.

The disposition effect is a well documented stylized fact of the literature analyzing individual investor behavior. According to the disposition effect, investors have a larger propensity to sell assets from their portfolios that were recent winners compared to stocks that were recent losers. It has been documented for US (Odean, 1998), Finnish (Grinblatt and Keloharju, 2001), Australian (Brown, Chappel, Rosa, and Walter, 2006) and Chinese (Feng and Seasholes, 2005) investors, among others. We confirm the presence of the disposition effect on the market for knock-out warrants, a market in which individual investors drive the order flow. As a marginal contribution, we show that the disposition effect is stronger for puts compared to calls, that is, when investors speculate on contractions. For a recent review on individual investor behavior, see Barber and Odean (2013).

Our highly stylized model is motivated by seminal theoretical papers as well as the empirical observation that individuals use financial markets for sensations seeking, i.e. to gamble (Dorn and Sengmueller, 2009; Dorn, Dorn, and Sengmueller, 2014; Kumar, 2009). The theoretical literature has used various assumptions to describe the behavior of individual investors. In seminal papers, noise traders introduced into rational expectation equilibrium models are often associated with individual investors who trade randomly due to exogenous reasons, like liquidity shocks (Kyle, 1985; Glosten and Milgrom, 1985). While these papers' main concern is market liquidity, we focus on individual investors' aggregate position in the knock-out warrant market when they randomly allocate their funds - similarly to noise traders.

This is consistent with investors betting on reversals: after recent appreciations of the underlying the value of calls increases, while the value of puts decreases. Hence, if investors have a larger propensity to close positions that secure gains, they will sell the calls, which is equivalent to betting on a price reversal. For example, the theory of realization utility proposed in Barberis and Xiong (2012) assumes that investors gain an extra utility from selling assets that have appreciated during the holding period. This naturally leads to the disposition effect and is also consistent with our findings.

Theoretical papers analyzing the strategic behavior of banks who issue innovative financial assets for individual investors is scarce. Kondor and Kôszegi (2015) build a model in which investors do not take into account that a bank has private information when it wants to sell an innovative asset to them. Compared to their model we only focus on knock-out warrants and analyze how the menu of warrants affects investor 
exposures. By focusing of short run effects we abstract from banks' strategic behavior, which would be a natural (though not trivial) next step.

The closest to our paper in terms of the type of data used is Baule (2011) who merges quote data with transactions data in order to recover the order flow of investors. However, Baule (2011) focuses on discount certificates and investigates how banks use anticipated order flow in setting their quotes. The German tax code is exploited for identification, which favors investments held over a year and find that investor demand is high for products that mature just over a year. In contrast, we focus on highly leveraged products, which are typically held for much shorter periods (often within day) and presumably for the reason to speculate on directional movements. Importantly, investors can only open long positions using discount certificates, while in our setting investors may just as easily open short positions. Thus, our design enables pessimists to easily participate which is better suited to analyze investors' aggregate speculative position.

In a broader sense, our interest in investor behavior and product design relates to the literature on how individual investors affect asset prices. Ben-David and Hirshleifer (2012) documents that investors are more likely to sell assets that gained or lost a significant amount since purchase, compared to ones that hardly changed in value. An (2016) builds on this pattern and shows that stocks with both large unrealized gains and losses produce abnormal returns. It is argued that this is a result of individual investors exerting selling pressure on these stocks, due to their large movements. We also find some indirect evidence in line with these findings. In particular, trading activity concentrates to the most levered warrants, which have the most volatile returns. While we do not address possible asset pricing implications of our findings, if banks hedge their open positions originating from the warrants market on the underlying's market, investor behavior could be transmitted.

There is a growing literature that analyzes the pricing of structured products. The dominating idea in this literature is the "life-cycle hypothesis". According to the lifecycle hypothesis issuers quote prices that contain higher margins at the beginning of the product's life (when investors are more likely to purchase the products) and decrease the margin during the product's life. Since many investors resell the products to banks before maturity, the banks profit from decreasing the margins over time. The reason banks are able to do this is that short selling of structured products is not allowed. The idea of a life cycle effect was put forward by Wilkens et al. (2003). Wilkens and Stoimenov (2007) study the pricing of leverage products similar to the ones in the current paper. They find that quoted prices significantly exceed upper hedging boundaries and also theoretical values. Henderson and Pearson (2011) provides evidence suggesting significant overpricing for retail structured products in the U.S. Compared to these papers we assume that warrants are priced fairly, and since we focus on the asymmetries of offered products in a static framework, the dynamics of margins should not play a significant role here.

Banks have been very active in designing innovative products in order to attract individual investors' attention. This started a literature that investigates the complexity and performance of these products. Célérier and Vallée (2017) show that as yields decreased during recent years banks offered more complex products in order to attract investors with lucrative headline returns. Compared to them we focus on a standardized segment of retail structured products and focus on how individuals use these to place speculative bets..$^{6}$

\footnotetext{
${ }^{6}$ While knock-out warrants are standardized, they are also difficult to be correctly appraised by
} 
The rest of the paper is organized as follows. The next section describes knock-out warrant and their trading environments. Section 3 introduces the model for individual investors' aggregate position and derives our testable hypotheses. Section 4 presents our empirical evidence, followed by discussions and concluding remarks.

\section{Market and product characteristics}

The German Derivatives Association provides an overview of exchange traded structured products..$^{7}$ The two largest exchanges where these products are traded are Euwax (European Warrant Exchange) in Stuttgart and Frankfurt Smart Trading, which is a specialized segment of Deutsche Börse in Frankfurt. Trading is concentrated to these exchanges, but most exchanges in Europe offer the opportunity for banks to issue structured products (and our data also comes from a smaller exchange).

There are over twenty banks actively issuing structured products. The issuing bank has to determine product characteristics and is required to continuously quote bid and ask prices, guaranteeing a liquid secondary market for its assets. Importantly, short selling is prohibited in these markets. This implies that banks may quote both ask and bid prices above the fair value of the derivatives.

When the product is introduced, the outstanding number of contracts is zero. The number of outstanding contracts increases if investors purchase products from the bank and decreases if investors resell the assets to the issuing bank. As investors may submit limit orders, it is possible for investors' orders to cross, which does not affect the outstanding number of contracts. However, in practice the bank is involved in most transactions.

A major difference between purchasing a structured product from a bank via a stock exchange and buying options in an options market is that the stock exchange does not require the bank to hold a margin account. In other words, by purchasing a structured product from a bank, investors hold the credit risk of the issuing bank. As Baule et al. (2008) show, the issuer's credit risk is in fact reflected in its quotes, i.e. issuers with lower credit risk are able to quote higher prices.

Products are broadly classified into two categories: investment products and leverage products. Investment products give over $95 \%$ of the volume. The most popular among them are those offering full or partial capital protection. Within leverage products, $\mathrm{KO}$ warrants are the most traded class, accounting for about half of the volume of leverage products.

\subsection{Product characteristics of knock-out warrants}

It is useful to fix ideas about the particular derivatives that are analyzed, as it is often difficult to navigate within the variety of retail structured products.

We have two types of options, knock-out calls (KO call) and knock-out puts (KO put). The KO call is a call option with a barrier and is known as a down-and-out call, as the barrier is set below ('down') the price of the underlying and the right to exercise disappears once the price hits the barrier ('out'). However, there is a twist. The option has a residual value if the barrier is hit, and the upper bound of the residual value is

individual investors. However, we do not address pricing in this paper.

${ }^{7}$ See Deutsche Derivative Verband (2014). 
the difference between the barrier and the strike. Formally, the payoff function of a $\mathrm{KO}$ call is

$$
\text { Payoff of KO call }= \begin{cases}S(T)-K & \text { if } S(t)>B \forall t, t_{0}<t<T \\ 0 \leq \text { Residual }(\leq B-K) & \text { if } \exists t: S(t) \leq B, t_{0}<t<T\end{cases}
$$

where $S(t)$ is the price of the underlying at time $t, t_{0}$ is the date when the product was issued, $B$ is the barrier price and $K$ is the strike price and they satisfy $B>K$ for the KO call options.

The upper bound of the residual is $B-K$. Once the price hits the barrier the bank has to close its hedging positions (i.e. sell the underlying), and if the price jumps below the barrier then the bank cannot close the position at the barrier. Hence, the residual value will depend on the price at which the bank manages to close its position. This essentially shifts the trade execution risk to the holders of the option 8 This is similar to a stop-loss order, where execution is not guaranteed.$^{9}$

$\mathrm{KO}$ put contracts are put options and can be approximated by up-and-out puts. The barrier is set above the price of the underlying ('up') and the right to exercise is lost once the barrier is crossed ('out'). Similarly to the KO call, there is a residual value if the barrier is hit. Formally, the payoff of a KO put is

$$
\text { Payoff of KO put }= \begin{cases}K-S(T) & \text { if } S(t)<B \quad \forall t, t_{0}<t<T \\ 0 \leq \operatorname{Residual}(\leq K-B) & \text { if } \exists t: S(t) \geq B, t_{0}<t<T\end{cases}
$$

where the barrier is always below the strike, $B<K \cdot{ }^{10}$

In Appendix C we compare the Delta and the Vega of a KO call with those of a vanilla call and a futures contract, in order to illustrate how $\mathrm{KO}$ warrants are priced relative to these derivatives 11 Here we only focus on leverage, which makes KO warrants unique.

Since the Delta of the KO call is always close to 1 , a first-order approximation for the value of a $\mathrm{KO}$ call is its intrinsic value, $S(t)-K^{\text {call }}$ and for a $\mathrm{KO}$ put it is $K^{\text {put }}-S(t)$. Exactly for this reason, banks often advertise such warrants as futures contracts, with an automatic stop-loss (instead of getting a margin call). Note that our model generates exactly these prices, as $C_{t}=S_{t}-K^{\text {call }}$ and $P_{t}=K^{\text {put }}-S_{t}$, due to the fact that we abstracted from knock-out events occurring before maturity.

Using these approximations to express the leverage of a $\mathrm{KO}$ call, one finds that

$$
\text { Leverage of } \mathrm{KO} \text { call } \approx \frac{S(t)}{S(t)-K^{\text {call }}}
$$

\footnotetext{
${ }^{8}$ This argument assumes that the banks always hedge their exposure. However, if banks do not completely hedge their exposure then they do not have to close their hedging positions if a KO event occurs. Hence, banks might be able to profit from not giving the maximum residual value to investors.

${ }^{9}$ Note that if the option reaches the expiry date without a knock-out event then the payoff of $S(T)-K$ is received at the expiry date, $T$, but if the barrier $B$ is hit then the residual value will be transferred to the investors' account a few business days after the knock-out event.

${ }^{10}$ In practice, there is also a multiplier that scales the KO products. Since this multiplier does not affect the analysis, we chose not to complicate the exposition with it.

${ }^{11}$ Delta measures the unit change in the derivative's price if the underlying's price increases by 1 unit. Vega measures the percent change in the proce of the derivative when the underlying's volatility increases by $1 \%$ point.
} 
It is clear from (1) that leverage explodes as the underlying's price approaches the strike price.

Figure 4 highlights how the leverage of the KO call is related to the leverage of the vanilla call and that of a futures.$^{12}$ As expected, the futures always has a leverage equal to the inverse of the required margin. The leverage of the vanilla call is close to flat, which highlights the fact that most of its value is the time value. To the contrary, the value of a $\mathrm{KO}$ call will be very close to the intrinsic value, which will imply that when its intrinsic value is low, its leverage will be high.

The mechanical relation of $\mathrm{KO}$ call and put prices, and also their leverage is illustrated in Figure 5. Suppose a bank wants to issue a new KO call. Then it has to determine the call's terms, e.g. its strike price, barrier and maturity. Figure 5 illustrates that the chosen strike price for the call has an important effect on the initial value and leverage of the new product. Importantly, the new call's strike may result in a call contract that is either much cheaper and has higher leverage compared to the already available put product, or much more expensive with a lower leverage.

To sum up, the KO call does seem to be closer to a futures contract than to a vanilla call (stable Delta close to 1), but notable differences still remain. The crucial property that sharply differentiates the KO call from both a vanilla call and a futures is its leverage, which is highly sensitive to the underlying's price. Importantly, when a bank introduces a new KO product it may significantly alter the prevailing asymmetries in the leverages of offered KO calls and KO puts. Since the product with the highest leverage will turn out to be the most popular product in this market, changes in the relative leverage of $\mathrm{KO}$ calls and $\mathrm{KO}$ puts will influence investors' aggregate exposure.

\section{A model of individual investor positions}

Consider a three period binomial tree, where $t \in\{0,1,2\}$. There is a single risky asset, which has a value of $S_{t}$ at $t$. Between periods the risky asset either increases with a factor of $u>1$ or decreases with a factor of $d<1$. For the sake of exposition, we are going to work with an equal probability tree, implying that the probability of moving up and down the tree between periods is always $1 / 2$. These probabilities also coincide with the risk-neutral measure, implying that $1=(d+u) / 2$, as we abstract from discounting. We normalize $S_{0}=1$. As a result, $S_{1} \in\{u, d\}$ and $S_{2} \in\left\{u^{2}, u d, d^{2}\right\}$.

There are individual investors who cannot trade directly with the underlying but can purchase warrants from a bank, who prices the warrants fairly. Trading between the bank and investors takes place in periods $t=0$ and $t=1$, while in period $t=2$ the warrants expire. Those purchasing warrants at $t=0$ may resell their warrants to the bank at $t=1$ or hold their warrants until maturity (until $t=2$ ). There are two warrants offered by the bank: one knock-out call, and one knock-out put.

Investors randomly choose between taking a long or a short position, and pick assets accordingly. Similarly, they hold on to their chosen assets for a random duration. At the beginning of trading periods $(t=0,1) n$ investors arrive, each endowed with $m$ money to invest. Each investor independently decides whether to take a long position or to take a short position, where the probability of going long is $1 / 2 \cdot{ }^{13}$ If an investor chooses to take a long position, she spends her money on knock-out calls, otherwise she

\footnotetext{
${ }^{12}$ Note that the parameters used for this figure are given in Table 8 in Appendix $\mathrm{C}$

${ }^{13}$ The results hold for any fixed probability of going long. The crucial assumption is its independence of the past returns of the underlying.
} 
purchases knock-out puts. Additionally, a fraction $\delta \in[0,1]$ of investors who bought warrants during $t=0$, resell their warrants to the bank during $t=1$.

Here is the timing of events:

$t=0 \quad 1 . S_{0}$ is revealed (and normalized to 1 ).

2. Trading takes place: $n$ investors arrive, who individually randomize between taking a long or a short position using their funds, $m$.

$t=1 \quad$ 1. $S_{1}$ is revealed.

2. Trading takes place: those who purchased securities in period 0 resell them with probability $\delta$. Additionally, $n$ investors arrive, who individually randomize between taking a long or a short position using their funds, $m$.

$t=2 \quad 1 . S_{2}$ is revealed.

2. Securities mature and are settled.

In the remainder of this section we first analyze investors' trading activity and aggregate position if they would have access to the futures market. This serves as a useful benchmark. Second, we turn to the case in which investors are faced with the two products offered by the bank.

\subsection{The futures market as a benchmark}

Consider a futures contract that expires at $t=2$. The futures contract serves as a benchmark, which allows us to analyze how investors would trade with futures if they had access to futures markets ${ }^{14}$ Importantly, we assume that a risk neutral market maker is able to take the other side of investors' net order flow, implying that individual investors' aggregate demand does not affect prices.

The futures market offers investors the opportunity to take long or short positions in the underlying risky asset. The value of a futures contract at $t$ is denoted by $F_{t}$. Since we abstract from discounting, the value of the futures always equals to the value of the underlying, that is $F_{t}=S_{t}$.

It is standard practice that trading with futures requires a margin account. That is, if an investor wants to open a futures position (buy or sell futures contracts), she needs to transfer the initial margin into the margin account as collateral. In reality the initial margin is typically set between $5 \%$ to $10 \%$ of the contract's value and its amount depends on the underlying asset's volatility. Let the initial margin be denoted by margin. We abstract from margin calls in our setting by assuming that

$$
\max \left\{1-d^{2}, u^{2}-1\right\}<\operatorname{margin},
$$

that is, the initial margin is large enough to cover all potential losses that may occur before maturity. For example, if an investor purchases one contract (takes a long position) at $t=0$, she has to post margin $\times S_{0}$ as collateral. In the worst case (from the investor's perspective), when the underlying depreciates to $S_{2}=d^{2}$, she loses $\left(1-d^{2}\right) S_{0}$, which is smaller than the collateral posted by inequality (2). Thus, the initial margin is large enough to cover even the largest losses.

\footnotetext{
${ }^{14}$ Additionally, banks often describe knock-out warrants as futures contracts without the inconvenience of margin requirements.
} 
Let $H_{0}^{F L}\left(H_{0}^{F S}\right)$ denote the total number of bought (sold) futures contracts by investors in period 0 . If investors individually randomize between buying and selling futures contracts, then the expected number of bought and sold contracts satisfy (using the expected value of the binomial distribution)

$$
E\left[H_{0}^{F L} \mid F_{0}\right]=E\left[H_{0}^{F S} \mid F_{0}\right]=\frac{\text { Expected total funds invested }}{\text { Initial margin } \times F_{0}}=\frac{n m / 2}{\operatorname{margin} \times F_{0}},
$$

since the total expected money flowing to buys and sells is $n \mathrm{~m} / 2$ and the initial margin requirement is margin. Investors buy and sell more contracts if (i) there is a higher number of them (higher $n$ ) (ii) investors have more money to invest (higher $m$ ) and if the initial margin required / value of a contract is smaller.

Importantly, investors buy and sell the same number of futures contracts in expectation. This result is consistent with how it is often thought about noise traders, namely, that they do not systematically buy or sell assets. As a result, on average, investors do not have an aggregate exposure to the underlying. Volumes of buys and sells are also symmetric.

The same argument applies for period $t=1$. In turn, no matter how the underlying evolves, in expectation investors have zero exposure in both trading sessions, which also implies that their aggregate position does not systematically vary with the underlying 15

To sum up, we emphasize the conditions required for the above result: (i) margin requirements for long and short contracts are not correlated with past returns, (ii) investors' preferences for opening new long (instead of short) positions are not correlated with past returns and (iii) investors' decision to close a position is not correlated with past gains/losses. We continue with the discussion of the knock-out warrant market, where due to different product characteristics, condition (i) will no longer hold, leading to systematic patterns in aggregate investor positions.

\subsection{Investors in the warrants market}

Consider knock-out warrants. A knock-out call offers long exposure and the knockout put offers short exposure. Similarly to the futures discussed above, they expire at $t=2$. Importantly, we assume that the strikes and barriers satisfy

$$
K^{\text {call }}=B^{\text {call }}<d^{2} \leq u^{2}<B^{\text {put }}=K^{\text {put }},
$$

where $K^{\text {call }}\left(K^{\text {put }}\right)$ is the strike price of the call (put) and $B^{\text {call }}\left(B^{\text {put }}\right)$ is the barrier of the call (put). Setting the barriers equal to the strikes helps our exposition, while setting the barriers outside of the underlying's range simplifies derivations, since it guarantees that no knock-out events occur before maturity (this is similar to inequality (2), which eliminates margin calls from the setup). ${ }^{16}$ As a consequence, the payoff of the warrants coincide with the payoff of vanilla options.

The call's payoff at $t=2$ is

$$
C_{2}=S_{2}-K^{\text {call }}
$$

\footnotetext{
${ }^{15}$ Note that this last statement would also hold if margin requirements would be different for long and short positions (but constant over time).

${ }^{16}$ This is also the empirically relevant case, as investors can only trade actively with a warrant until it has not been knocked-out.
} 
while the put's payoff is

$$
P_{2}=K^{p u t}-S_{2} \text {. }
$$

Following the simple structure, it is straightforward to determine the fair prices of the warrants for $t=0,1$. In particular, the solutions are $C_{t}=S_{t}-K^{\text {call }}$ and $P_{t}=K^{\text {put }}-S_{t} \cdot 17$

E.g. if $S_{1}=u$, then under the risk-neutral measure

$$
C_{1}=E\left[C_{2} \mid S_{1}=u\right]=E\left[S_{2}-K^{\text {call }} \mid S_{1}=u\right]=\left(u^{2}+u d\right) / 2-K^{\text {call }}=u-K^{\text {call }} .
$$

One of the features that separates futures markets from bank issued knock-out warrants is that in the latter investors are not required to post margins as investors cannot lose more than the invested amount.

Now consider the distribution of trading activity. Let $H_{t}^{C}\left(H_{t}^{P}\right)$ denote the gross number of calls (puts) that investors purchase from the bank at $t$. During $t=0$, the expected number of calls and puts bought by investors is (where the expectation is over individual investors' randomization over going long or short)

$$
E\left[H_{0}^{C} \mid S_{0}\right]=\frac{n m}{2 C_{0}}=\frac{n m}{2\left(S_{0}-K^{\text {call }}\right)}, \quad E\left[H_{0}^{P} \mid S_{0}\right]=\frac{n m}{2 P_{0}}=\frac{n m}{2\left(K^{\text {put }}-S_{0}\right)},
$$

that is, all else equal, investors purchase higher number of contracts if (i) there are a higher number of investors (higher $n$ ), (ii) investors have more money to spend (higher $m$ ) and (iii) if the given product is cheaper (lower $C_{0}$ or lower $P_{0}$ ). Since all warrants are priced fairly, the expected profit of purchasing any calls or puts is zero. However, their payoff, in general, depends on the evolution of the risky asset $\left(S_{t}\right)$, implying that they have exposure to the underlying. Interestingly, the exposure a contract offers is independent of its price, since option payoffs are linear in the underlying. Formally, let $V$ be the value of investors' warrants at the end of period $t=0$,

$$
V_{0}=H_{0}^{C}\left(S_{0}-K^{\text {call }}\right)+H_{0}^{P}\left(K^{\text {put }}-S_{0}\right) .
$$

We define $E X P_{t}$ as investors' aggregate exposure (to which we will also refer as investors' aggregate position) to the underlying at the end of period $t$ (that is, after investors' purchase decisions), which, at $t=0$, is equal to

$$
E X P_{0}=\frac{\Delta V_{0}}{\Delta S_{0}}=H_{0}^{C}-H_{0}^{P}
$$

Equation (4) can be interpreted as follows. Suppose investors hold $H_{0}^{C}$ calls and $H_{0}^{P}$ puts at the end of period $t=0$, and the price of the underlying, $S_{0}$, increases by one unit. Then the aggregate value of investors' portfolio increases by $H_{0}^{C}-H_{0}^{P}$. Thus, an additional call (put) contract increases (decreases) investors' exposure by one unit, irrespective of the contract's properties (i.e. barriers and strikes). This implies that buying a cheap contract has the same effect on investors' exposure as buying an expensive one. The expectation of exposure is equal to

$$
E\left[E X P_{0} \mid S_{0}\right]=E\left[H_{0}^{C} \mid S_{0}\right]-E\left[H_{0}^{P} \mid S_{0}\right]=\frac{n m}{2} \frac{K^{\text {call }}+K^{\text {put }}-2 S_{0}}{\left(S_{0}-K^{\text {call }}\right)\left(K^{\text {put }}-S_{0}\right)}
$$

\footnotetext{
${ }^{17}$ In this setup the warrants are similar to real life knock-out warrants, since their value also falls close to their intrinsic value.
} 
Since the denominator in (5) is always positive, the sign of the aggregate exposure depends on the level of the strikes, $K^{\text {call }}$ and $K^{\text {put }}$, relative to $S_{0}$. When $K^{\text {call }}$ and/or $K^{\text {put }}$ is relatively large (but still satisfying the inequalities in (3p) then the exposure is positive: if the underlying increases the combined value of the warrants increases. The intuition is simple. When $k^{\text {call }}$ and/or $K^{\text {put }}$ is relatively large then the price of a call, $C_{0}$ will be small compared to the price of a put, $P_{0}$. This results in an investor portfolio consisting of more call contracts than put contracts, in expectation. Hence, investors, on average, gain if the underlying increases and lose if the underlying decreases. Investors' expected exposure is only zero if $S_{0}$ is the arithmetic mean of the strikes, as in that case the calls and puts trade at the same price.

Now consider the trading session at $t=1$. The new traders take positions similarly as before, implying that the expected change in investors' aggregate position from $t=0$ to $t=1$ will be

$$
\begin{aligned}
& E\left[E X P_{1}-E X P_{0} \mid S_{1}, S_{0}\right]= \\
& \qquad \frac{n m}{2}\left[\frac{K^{\text {call }}+K^{\text {put }}-2 S_{1}}{\left(S_{1}-K^{\text {call }}\right)\left(K^{\text {put }}-S_{1}\right)}-\delta \frac{K^{\text {call }}+K^{\text {put }}-2 S_{0}}{\left(S_{0}-K^{\text {call }}\right)\left(K^{\text {put }}-S_{0}\right)}\right]
\end{aligned}
$$

where $E\left[E X P_{1} \mid S_{1}, S_{0}\right]$ is the expected exposure of investors at the end of $t=1$, conditional on the history of the underlying and $\delta$ is the fraction of investors who choose to resell their warrants to the bank before they expire.18 The first term in brackets corresponds to the total exposure of those investors who arrived in period 1 , while the second term captures resells of investors who arrived in period 0. It is clear from (6) that when $S_{1}=d$ is realized, then the price of the call depreciates, and, simultaneously, the price of the put appreciates. Thus, investors who arrive in period 1 take a longer position compared to period 0 investors because calls are now relatively cheaper than previously. Similarly, when $S_{1}=u$ is realized, investors decrease their aggregate position. Thus, investors aggregate position suggests that they bet on price reversals.

The following proposition summarizes the main predictions from the model:

Proposition 1 1. Share of transactions involving calls does not depend on past returns.

2. Share of call contract trading value is positively correlated with past returns,

$$
\operatorname{Cov}\left[\frac{\left[\delta H_{0}^{C}+H_{1}^{C}\right] C_{1}}{n m+\delta\left[H_{0}^{C} C_{1}+H_{0}^{P} P_{1}\right]}, S_{1}-S_{0}\right]>0
$$

3. Share of call contract volumes is negatively correlated with past returns,

$$
\operatorname{Cov}\left[\frac{\delta H_{0}^{C}+H_{1}^{C}}{H_{1}^{C}+H_{1}^{P}+\delta\left[H_{0}^{C}+H_{0}^{P}\right]}, S_{1}-S_{0}\right]<0 .
$$

4. Investors bet on price reversals, implying $\operatorname{Cov}\left[E X P_{1}-E X P_{0}, S_{1}-S_{0}\right]<0$

\footnotetext{
${ }^{18}$ Note that expectations are taken over individual randomizations on whether to take a long or a short position.
} 
The proofs are straightforward, and shown in Appendix A. Since investors individually randomize between taking long or short positions and the probability of reselling warrants to the bank is independent of past returns, the share of transactions involving calls does not depend on past returns.

The second statement is that the share of call contract value (value of exchanged call contracts normalized by the total value of exchanged call and put contracts) is increasing with past returns. The intuition for this result is that if the underlying appreciates, the value of calls held by investors increases relative to puts. In turn, since the selling decision is independent of past returns, the calls resold by investors will have higher value than the puts.

Third, the share of call contract volume is decreasing with past returns. The idea is that after appreciations of the underlying call contracts become relatively more expensive, implying that for the same amount of investment, investors can only purchase a lower number of call contracts.

Finally, investors take positions as if they were betting on price reversals. This is the most surprising prediction of the model, given that purchasing and selling decisions are independent of past returns. Since the price of calls (puts) is monotone increasing (decreasing) in the underlying, if the underlying increases puts are going to be cheaper than calls and this will lead new investors to purchase a higher number of puts, effectively betting on a reversal.

It is important to emphasize that these results are conditional on not hitting any of the barriers, as we have assumed in (3). The moment a barrier is hit, investors' position will be closed automatically, implying that in that moment they are (passively) reinforcing market movements. However, our focus is on understanding investors' purchasing and reselling decisions, which are also conditional on a warrant being prior to a knock-out event.

To conclude, while the exposure individual investors may take with calls and puts is very similar to the exposure provided by futures, the contract features of knock-out warrants are fixed in the short-run, which leads to an asymmetry of product characteristics between offered calls and puts. In turn, if individual investors allocate their funds randomly, their aggregate exposure will systematically vary with the asymmetries of the available menu. While the asymmetries in this simplified setup are only driven by the evolution of the underlying, in reality banks have the option to strategically time the introduction of new warrants, which gives them the (potentially valuable) power to influence individual investors' aggregate position.

\section{Empirical analysis}

We have obtained transactions data from a bank on KO calls and puts that have the German DAX index as their underlying. Our data consists of all transactions that took place between the bank and investors from December 2013 to April 2014 (100 trading days) and includes all KOs issued on the DAX by our bank during this period ${ }^{19}$ There were $6 \mathrm{KO}$ calls and $4 \mathrm{KO}$ puts actively traded in the given sample period (see Figure 2). For each transaction we can observe a time stamp, the number of contracts exchanged, the price per contract and, most importantly, the sign of the

\footnotetext{
${ }^{19}$ I.e. investor-investor transactions are not recorded, as the bank did not participate in these. Investor-investor transactions happen when investors submit orders that cross within the bid and ask prices set by the bank.
} 
trade. That is, we know whether investors bought contracts from or resold contracts to the issuing bank. This allows us to analyze investors' aggregate position in all issues throughout our sample.

Table 1 provides descriptives for the transactions data. Note that we have omitted settlement transactions occurring after maturity (3 issues) or a knock-out event (4 issues). For both calls and puts there are more transactions in which investors purchase contracts than resell contracts. Nevertheless, the large number of investor sells suggests that the holding period of these products is short and that the majority of investors does not wait until maturity.

The median transaction exchanges contracts worth around $€ 500$, while the mean value is over $€ 1600$, suggesting a highly skewed distribution. Also, sell transactions are larger, on average, for both calls and puts, which is consistent with investors' higher willingness to realize gains than losses.

KO puts are slightly more popular among investors than calls, which is likely to reflect that it is more difficult to find adequate substitutes for puts. However, the leverages of calls and puts are similarly high, above 13, on average and also vary a lot, with standard deviations above 4 .

For the analysis we restrict the sample by focusing on the highest levered call issue and highest levered put issue on any given day. As Figure 8 shows, the highest leveraged product is, by far, the most popular one. ${ }^{20}$ This implies that whenever a bank issues a new call or put that has higher leverage than the already available ones, it is likely to attract most of the trading activity. Additionally, we omit the largest transactions by dropping buy transactions who's value exceeds $€ 33333$ and sell transactions who's volume exceeds 4000 contracts. These approximately constitute the top percentile of their respective distributions.

Table 2 shows the descriptives of the selected sample. By keeping the highest levered products on each day we loose about $11 \%$ of the transactions. The mean value and volume of contracts decreases due to the elimination of the largest trades, while they increase as a result of eliminating lower levered issues.

We aggregate our data to the daily level, where we carry out our main analysis. Descriptives are provided in Table 3. Using our selected sample, we compute the total number of contracts bought and sold by investors during day $t$ of issue $i$ and also their difference. Similarly, we count the buy and sell transactions and their difference. This leaves us with 100 observations for calls and puts each. Note that the difference between buys and sells has a standard deviation similar to buys and sells, which suggests that buys and sells are positively correlated, i.e. day trading gives a significant portion of the volume. Nevertheless, on a median (and mean) day, investors tend to purchase more contracts than sell, which suggests that at least some investors undertake longer holding periods. This is also confirmed, for example, by Figure 1, which indicates large persistence of investors' aggregate position.

To measure the asymmetry in the menu of offered contracts, we define DLevt as the difference between the Log leverages of the highest levered call and put:

$$
D L e v_{t}=\ln \left(\frac{S_{t}}{S_{t}-K^{\text {call }}}\right)-\ln \left(\frac{S_{t}}{K^{\text {put }}-S_{t}}\right)
$$

where $S_{t}$ is the closing price of the underlying and $K^{\text {call }}\left(K^{\text {put }}\right)$ is the strike of the highest levered call (put). We refer to $D L e v_{t}$ as the leverage differential. Its distribution

\footnotetext{
${ }^{20}$ Note that the result also holds if trading activity is measured by the number of transactions or the trading value.
} 
is shown in Table 3, while its evolution is also illustrated on Figure 3. Additionally, Table 3 also shows the distribution of the $(\log )$ returns on the DAX index $(\times 100)$ during our sample period.

In order to disentangle the effects of past returns and the asymmetric menu of the offered contracts we estimate the following specification on the daily data:

$$
\begin{array}{r}
\text { Buys }_{i, t}-\text { Sell }_{i, t}=\beta_{1} R_{t-1}^{D A X}+\beta_{2} P u t_{i} \times R_{t-1}^{D A X}+\gamma_{1} \text { DLev }_{t-1}+\gamma_{2} P u t_{i} \times \text { DLev }_{t-1}+ \\
\delta X_{i, t-1}+\alpha_{(i)}+\epsilon_{i t},
\end{array}
$$

where $i$ identifies the warrant issue and $t$ is the date. The dependent variable is the net purchase of investors measured by the difference between the total number of contracts bought $\left(\right.$ Buys $\left._{i, t}\right)$ and sold $\left(\right.$ Sell $\left._{i, t}\right)$ during day $t . R_{t-1}^{D A X}$ is the return of the DAX index from the close of $t-2$ to the close of $t-1$. Put is an indicator for the issue being a put and $D L e v_{t-1}$ is the leverage differential at the closing time of the previous trading day. ${ }^{21}$ A set of controls known at $t-1$ including the $P u t_{i}$ indicator, the total number of outstanding contracts of issue $i$, days since issuance and days to maturity are included in $X_{i, t-1}$. The constant term may be issue-specific, i.e. (7) may be estimated using fixed-effects.

If investors systematically bet on price reversals, as predicted by our model, we expect $\beta_{1}<0$ and $\beta_{1}+\beta_{2}>0$. That is, following an increase in the DAX index, investors should decrease their holdings of call contracts and increase their holdings of put contracts.

Parameters $\gamma_{1}$ and $\gamma_{2}$ capture the mechanical effect leading to Proposition 1. If investors allocate their funds randomly we expect $\gamma_{1}>0$ and $\gamma_{1}+\gamma_{2}<0$, that is, when a higher leverage differential leads investors to purchase a higher number of call contracts as they are relatively cheap compared to the offered put contract.

\subsection{Results}

Does investors' aggregate position systematically vary with the available menu of contracts and/or with past returns? We have already shown that the most levered products are the most popular ones within puts and within calls (Figure 8). Now we turn to the more interesting question, whether asymmetries in the product characteristics of the offered calls and puts systematically affects the position investors take.

Table 4 presents the benchmark results of estimating 7. Estimates from column (1) confirm the prediction of Proposition 1. Investors, on the aggregate bet on price reversals. A $1 \%$ percent increase in the DAX index (which also happens to be close to its standard deviation) is associated with investors selling 1829 call contracts and buying similar number of put contracts (the raw standard deviation of the dependent variable is 8300 contracts) during the next trading day, leading to a net change in their position of over 3600 contracts.

Controlling for asymmetric leverage and product characteristics (column (2)) shrinks this association by almost a third. That is, investors tend to purchase a higher (lower) number of call (put) contracts when the leverage of the highest levered call is higher

\footnotetext{
${ }^{21} D L e v_{t-1}$ is also the approximate difference between the put's and call's price. A call contract's price can be approximated by $C_{t} \approx S_{t}-K^{\text {call }}$ and its leverage by $C_{t}^{L e v} \approx S_{t} /\left(S_{t}-K^{\text {call }}\right)$. Similarly, a put contract's price is close to $P_{t} \approx K^{\text {put }}-S_{t}$ and its leverage $P_{t}^{L e v} \approx S_{t} /\left(K^{\text {put }}-S_{t}\right)$. It follows that $D L e v_{t-1}=\ln C_{t}^{L e v}-\ln P_{t}^{L e v}=\ln P_{t}-\ln C_{t}$.
} 
than the leverage of the highest levered put. Adding issue fixed effects further reduces the association. The results suggest that about two fifths of the association between past returns and investor activity is due to the asymmetric menu of offered contracts.

The last two columns of Table 4 decompose the results to investors' buying and selling activity. These suggest that past returns significantly influence investors' selling decisions while playing no role in their purchasing decisions. To the contrary, asymmetric leverages play a more important role in the purchasing decision.

Taken together, investors tend to bet on price reversals. However, part of this effect is mechanical: even if they were to randomly allocate their funds between the highest levered call and put, the result would follow. Nevertheless, their selling decision reinforces the effect: after increases (decreases) in the DAX index, investors tend to sell a higher number of call (put) contracts, taking profits. This is consistent with the well documented disposition effect.

Is there heterogeneity in the results? To address this, we rerun the regressions of Table 4 on large and small trades, separately. Results are tabulated in Tables 5.6. We define large (small) trades as a transaction involving over (at most) 200 contracts, which roughly corresponds to the 75 th percentile of its distribution, i.e. $75 \%$ of transactions involve less than 200 contracts. However, dividing the sample this way proxies for relatively wealthier investors in a noisy fashion. It would be a perfect proxy if investors who purchase at most (over) 200 contracts always sell at most (over) 200 contracts with a transaction. If investors build up their positions over time with multiple transactions below the 200 threshold and sell all of their contracts (the total exceeding 200) with a single transaction, then their purchasing activity is (mis)classified as small and their selling is classified as large. ${ }^{22}$

The estimates in Tables 5 6 6 suggest significant differences between the behavior of wealthier and less wealthier investors. First, the asymmetric menu accounts for a larger fraction of the observed association between past returns and investors' positions when it comes to wealthier/larger traders. In particular, for larger traders it accounts for about half of the association (symmetrically for calls and puts) while for smaller traders it does not affect the slope for put contracts and accounts for less than half for calls. This suggests that people betting in smaller amounts are more heavily influenced by past returns.

Second, smaller traders' purchasing decisions are also influenced by past returns while larger traders' is not. The estimates in Table 6 imply that even after controlling for the asymmetries in the available menu, smaller investors bet on price reversals by purchasing more calls (puts) after recent negative (positive) returns of the DAX.

Since the value of transactions is heavily skewed, one concern is that the benchmark results might be driven my the behavior of a few large investors/trades, even after eliminating the largest trades from the sample. For example, sorting (investors purchasing) transactions into deciles by the number of contracts involved, one finds that the top quartile of transactions (i.e. transactions involving over 200 contracts) accounts for over $80 \%$ of the volume. Therefore, as a robustness check, we count the purchasing and selling transactions by each day and issue and rerun the regressions using the difference between purchasing and reselling transactions as a dependent variable. This gives equal weight to each transaction, i.e. overweighting the behavior of small traders.

\footnotetext{
${ }^{22}$ Similarly, if investors buy over 200 contracts with a single transaction and sell off their contracts in smaller than 200 bundles, their buying activity would be classified as large while their selling as small.
} 
Table 7 shows the results. The results are qualitatively closest to the results on small trades (Table 6). That is, past returns seem to play an important role both in the purchasing and in the selling decision even after controlling for the asymmetric leverage of calls and puts. Surprisingly, though, the leverage differential enters the fixed effects specifications significantly. This suggests that investors place buy orders more frequently (compared to sell orders) if the product is offering relatively high leverage. In other words, investors consider the relative leverage of calls and puts when deciding on the direction of their bets, which goes against our assumption that investors choose the side of their bets randomly. The effect is also asymmetric: for puts its negligible while for calls it is large. This would imply that there are numerous, albeit relatively small, speculators, who take long positions if the leverage of the highest levered call is sufficiently high and do not consider taking short positions.

To take advantage of our transaction level data, we plot the within day distribution of transactions on Figure 9. Most transactions occur right after the exchange opens and just before the exchange closes for the day. In particular, due to day trading, the propensity to buy is largest in the morning hours and the propensity to sell is largest during the hours before closing.

Figure 10 breaks down trading intensities by the sign of the within day return of the underlying. Consistent with the disposition effect, investors are more likely to submit sell orders for calls during the afternoon if the underlying's price increased within the day. Similarly, they are more likely to sell puts during the afternoon if the price decreased during the day. This pattern suggests that day traders are also prone to the disposition effect.

\section{Discussion}

The data confirms our main hypothesis of investors betting on price reversals. The asymmetric leverage of offered call and put warrants induces investors to bet on price reversals, on aggregate, even if they were to choose the direction of their bets randomly at the individual level. In addition, the data suggests that individuals bet on price reversals even after controlling for the mechanical channel.

The results are also consistent with investors' sensation seeking. Kumar (2009) demonstrates that individual investors who are likely to participate in state lotteries are also more likely to be drawn to high volatility (lottery-type) assets in financial markets. Analyzing individual investors' portfolio using data from a German brokerage in addition to survey data, Dorn and Sengmueller (2009) show that investors who enjoy gambling trade more frequently. Investors are also more likely to gamble on financial markets when other alternatives are less appealing. Dorn et al. (2014) provides evidence from both the US and Germany suggesting that lower prizes on national lotteries is associated with an increase of small trades in speculative stocks. That is, individual investors substitute between gambling on lotteries and gambling on financial markets. We also provide suggestive evidence on sensation seeking. In particular, the estimates of Table 7 suggest that investors tend to place long bets more frequently if the leverage of the (highest levered) call warrant is larger. That is, higher leverage attracts more bets.

We find that past returns strongly influence the selling decision of investors. Our results are consistent with the well documented disposition effect. Using data on individual investors' trading accounts provided by a brokerage, Odean (1998) finds that investors have a much stronger tendency (a disposition) to sell winner stocks from 
their portfolios than losers. Grinblatt and Keloharju (2001) provides evidence for the disposition effect from Finland. Dhar and Zhu (2006) and Feng and Seasholes (2005) argue that the disposition effect is weaker for sophisticated/wealthier investors. We complement these papers by providing evidence for the disposition effect in a setting where taking long and short positions is equally convenient for individual investors by using $\mathrm{KO}$ warrants. We show that the disposition effect is present on both sides. Individuals tend to sell more calls (puts) after recent increases (decreases) in the underlying. That is, they are more likely to sell their warrants after it has appreciated. We also provide suggestive evidence that smaller investors are more heavily influenced by past returns. In particular, we show that investors who gamble in smaller amounts, tend to bet on price reversals, i.e. they purchase more calls (puts) after declines (increases) in the underlying. This holds after controlling for leverage. On the other hand, past returns seem to have similar effects on the selling decisions of both larger and smaller investors.

If a fraction of investors believe that the underlying's price exhibits mean reversion, then betting on price reversals is a legitimate strategy (before transaction costs), which would directly lead to our empirical results. There is evidence from lab experiments suggesting that people mistakingly extrapolate random series. Andreassen and Kraus (1990) find that if people familiar with basic economics are presented with a sample series of a stock price that has a visible trend, subjects are likely to extrapolate that trend. Also, if the presented series does not exhibit a trend, people extrapolated mean reversion. Weber and Camerer (1998) and more recently Jiao (2017) also use lab experiments to determine the possible mechanisms that lead to the disposition effect and present evidence in favor of biased beliefs toward mean reversion.

The two competing explanations in Jiao (2017) are the preference based explanation and the belief based explanation. While the belief in mean reversion falls in the latter, prospect theory is the most prominent candidate in explaining the disposition effect. In particular, when risk attitudes are different for gains and losses, investors might be risk seeking if they hold losers and therefore choose not to sell the loser. On the other hand, in the domain of gains, investors might be more risk-averse, which induces them to close their positions. Jiao (2017) provides evidence for the belief based explanation. The disposition effect is strongest in those subjects who predict more mean reversion.

Our evidence is also consistent with investor overconfidence. Tables 6 6 7 and Figure 10 suggest that purchase decisions - especially for calls - are affected by past returns. Investors' decision to buy also depends on within day movements. In particular, investors seem to be following a "double down" strategy: they are more likely to purchase calls and puts at the end of the day if their respective values declined during the day. This is consistent with the hypothesis of Ben-David and Hirshleifer (2012), who suggest the following description of an overconfident investor: when the price of the chosen product rises, overconfident investors believe that everything went as planned and realize the gains. However, when the chosen product depreciates, overconfident investors now see an even bigger opportunity to gain, therefore they increase their holdings of the given product.

\section{Concluding remarks}

We analyze individual investors' trading activity, focusing on how past returns affect their aggregate order flow in the market of knock-out warrants. This market is at- 
tractive to carry out such an analysis as individuals are arguably the only traders and taking long and short positions in a given underlying is equally convenient for investors.

Our results suggest that past returns play an important role in investors' trading activity. Even after controlling for mechanical effects due to the asymmetric leverages of offered contracts we find that investors' aggregate trading activity is consistent with them betting on price reversals. More detailed analysis reveals that this is mostly due to their selling decisions, that is, investors are more likely to sell warrants after they have appreciated. This finding is consistent with the disposition effect. Additional results suggest that smaller investors actively bet on price reversals through their purchasing decisions, especially after depreciations of the underlying.

The main limitations of the paper are that we cannot link transactions to individuals (and their characteristics) and also that we do not consider the strategic behavior of the supply side, but assume that it is competitive.It is plausible that the behavior of individual investors influences bank's strategies. E.g. banks may strategically time the introduction of new warrants and they may strategically set quotes for their products. For purposes of risk and/or liquidity management banks might be inclined to design products that leave individual investors systematically exposed to the underlying, on average. Also, since the bank has the information advantage of knowing the number of outstanding contracts, it may find it optimal to use this information when setting its quotes, which also affects investor positions. Hence, a better understanding of the supply side would be a natural next step. 


\section{References}

An, Li (2016), "Asset Pricing When Traders Sell Extreme Winners and Losers." Review of Financial Studies, 29, 823-861.

Andreassen, Paul B. and Stephen J. Kraus (1990), "Judgmental extrapolation and the salience of change." Journal of Forecasting, 9, 347-372.

Barber, Brad M. and Terrance Odean (2013), "Chapter 22 - the behavior of individual investors." volume 2 of Handbook of the Economics of Finance, 1533 - 1570, Elsevier.

Barberis, Nicholas and Wei Xiong (2012), "Realization utility." Journal of Financial Economics, 104, 251-271.

Baule, Rainer (2011), "The order flow of discount certificates and issuer pricing behavior." Journal of Banking \& Finance, 35, 3120 - 3133.

Baule, Rainer, Oliver Entrop, and Marco Wilkens (2008), "Credit risk and bank margins in structured financial products: Evidence from the German secondary market for discount certificates." Journal of Futures Markets, 28, 376-397.

Ben-David, Itzhak and David Hirshleifer (2012), "Are Investors Really Reluctant to Realize Their Losses? Trading Responses to Past Returns and the Disposition Effect." Review of Financial Studies, 25, 2485-2532.

Brown, Philip, Nick Chappel, Ray Da Silva Rosa, and Terry Walter (2006), "The Reach of the Disposition Effect: Large Sample Evidence Across Investor Classes-super-." International Review of Finance, 6, 43-78.

Célérier, Claire and Boris Vallée (2017), "Catering to Investors through Security Design: Headline Rate and Complexity." Quarterly Journal of Economics (forthcoming).

Deutsche Derivative Verband (2014), "The structured products sector in figures." URL http://www.derivateverband.de/ENG/Publications/Factbook.

Deutsche Derivative Verband (2016), "Market Volume in Derivatives." URL http: //www.derivateverband.de/ENG/Statistics/MarketVolume.

Dhar, Ravi and Ning Zhu (2006), "Up close and personal: Investor sophistication and the disposition effect." Management Science, 52, 726-740.

Dorn, Anne Jones, Daniel Dorn, and Paul Sengmueller (2014), "Trading as gambling." Management Science, 61, 2376-2393.

Dorn, Daniel and Paul Sengmueller (2009), "Trading as Entertainment?" Management Science, 55, 591-603.

Feng, Lei and Mark S. Seasholes (2005), "Do Investor Sophistication and Trading Experience Eliminate Behavioral Biases in Financial Markets?" Review of Finance, 9, 305-351.

Glosten, Lawrence R. and Paul R. Milgrom (1985), "Bid, ask and transaction prices in a specialist market with heterogeneously informed traders." Journal of Financial Economics, 14, 71-100. 
Grinblatt, Mark and Matti Keloharju (2001), "What makes investors trade?" The Journal of Finance, 56, 589-616.

Henderson, Brian J. and Neil D. Pearson (2011), "The dark side of financial innovation: A case study of the pricing of a retail financial product." Journal of Financial Economics, 100, $227-247$.

Jiao, Peiran (2017), "Belief in mean reversion and the disposition effect: An experimental test." 18, 29-44.

Kaniel, Ron, Shuming Liu, Gideon Saar, and Sheridan Titman (2012), "Individual Investor Trading and Return Patterns around Earnings Announcements." Journal of Finance, 67, 639-680.

Kaniel, Ron, Gideon Saar, and Sheridan Titman (2008), "Individual Investor Trading and Stock Returns." Journal of Finance, 63, 273-310.

Kondor, Péter and Botond Kőszegi (2015), "Cursed financial innovation." Mimeo.

Kumar, Alok (2009), "Who Gambles in the Stock Market?" The Journal of Finance, 64, 1889-1933.

Kyle, Albert S (1985), "Continuous Auctions and Insider Trading." Econometrica, 53, $1315-35$.

Odean, Terrance (1998), "Are Investors Reluctant to Realize Their Losses?" The Journal of Finance, 53, 1775-1798.

Rubinstein, M. and E. Reiner (1991), "Breaking Down the Barriers." RISK, 4.

Weber, Martin and Colin F. Camerer (1998), "The disposition effect in securities trading: an experimental analysis." Journal of Economic Behavior \& Organization, $33,167-184$.

Wilkens, Sascha, Carsten Erner, and Klaus Röder (2003), "The Pricing of Structured Products in Germany." The Journal of Derivatives, 11, 55 - 69.

Wilkens, Sascha and Pavel A. Stoimenov (2007), "The pricing of leverage products: An empirical investigation of the German market for 'long' and 'short' stock index certificates." Journal of Banking \& Finance, 31, 735 - 750.

\section{A Proofs}

Proof of Proposition 1 .

1. By definition, the share of transactions involving calls is i.i.d. and the probability of resells, $\delta$, is also independent of all variables.

2. Using that $E\left[S_{1}-S_{0}\right]=0$, the covariance may be written as

$$
E\left[\frac{\left[\delta H_{0}^{C}+H_{1}^{C}\right] C_{1}}{n m+\delta\left[H_{0}^{C} C_{1}+H_{0}^{P} P_{1}\right]}\left(S_{1}-S_{0}\right)\right],
$$


Let the share of call contract trading value be denoted by $f\left(S_{1}, L_{0}, L_{1}\right)$, where $L_{t}$ is the number of traders who arrive in period $t$ and decide to open a long position (they are binomially distributed i.i.d. random variables). The expectation in (1) will always be positive because taking $L_{0}$ and $L_{1}$ fixed the expectation can be written as

$$
\frac{1}{2}(u-1)\left[f\left(u, \overline{L_{0}}, \overline{L_{1}}\right)-f\left(d, \overline{L_{0}}, \overline{L_{1}}\right)\right]
$$

which will always be positive as $f(\cdot)$ is increasing in $S_{1}$. Since this holds for all realized values of $L_{0}$ and $L_{1}$, it also holds in expectation.

3. The proof follows the same logic as the previous one.

4. The covariance may be written as

$$
E\left[\left(H_{1}^{C}-H_{1}^{P}-\delta\left(H_{0}^{C}-H_{0}^{P}\right)\right)\left(S_{1}-S_{0}\right)\right]=E\left[\left(H_{1}^{C}-H_{1}^{P}\right)\left(S_{1}-S_{0}\right)\right]
$$

where the equality follows from the fact that $L_{0}$ and $S_{1}$ are independent, that is $E\left[\left(H_{0}^{C}-H_{0}^{P}\right)\left(S_{1}-S_{0}\right)\right]=\left(H_{0}^{C}-H_{0}^{P}\right) E\left[S_{1}-S_{0}\right]=0$. Then for all realizations of $L_{1}$, the covariance simplifies to

$$
\frac{1}{2}(u-1)\left[\frac{L_{1} m}{u-K^{\text {call }}}-\frac{L_{1} m}{d-K^{\text {call }}}+\frac{\left(n-L_{1}\right) m}{K^{\text {put }}-d}-\frac{\left(n-L_{1}\right) m}{K^{\text {put }}-u}\right]
$$

which is always negative as $d<u$.

\section{B Tables and Figures}

Table 1: Descriptive statistics of transaction level data, whole sample. This table shows the distribution of selected variables for all investor initiated transactions. Settlement transactions following maturity or a knock-out event are excluded. Variables are defined from the investors' perspective, i.e. "Value of buys" corresponds to the number of euros paid by the investor as part of a transaction in which the investor bought contracts from the issuing bank.

\begin{tabular}{lccrrrrr}
\hline & Obs & Mean & Stdev & p10 & p50 & p75 & p99 \\
\hline & Call contracts & & & & & \\
\hline Value of buys (euros) & 5284 & 1624 & 4762 & 117 & 519 & 1271 & 19566 \\
Value of sells (euros) & 4005 & 2028 & 5199 & 122 & 613 & 1589 & 23190 \\
Leverage of buys & 5284 & 13 & 4.5 & 8.1 & 12 & 15 & 26 \\
Volume of buys (\# of contracts) & 5284 & 204 & 674 & 15 & 65 & 157 & 2400 \\
Volume of sells (\# of contracts) & 4005 & 244 & 712 & 15 & 76 & 200 & 3000 \\
\hline & Put contracts & & & & & \\
\hline Value of buys (euros) & 6537 & 1881 & 6478 & 98 & 472 & 1286 & 23153 \\
Value of sells (euros) & 4754 & 2463 & 7734 & 120 & 574 & 1668 & 34238 \\
Leverage of buys & 6537 & 14 & 4.9 & 9.2 & 14 & 17 & 32 \\
Volume of buys (\# of contracts) & 6537 & 277 & 1032 & 15 & 63 & 200 & 3000 \\
Volume of sells (\# of contracts) & 4754 & 349 & 1237 & 18 & 90 & 200 & 5000 \\
\hline
\end{tabular}


Table 2: Descriptive statistics of transaction level data, selected sample. This table shows the statistics of Table 1 for the selected sample. The following transactions are excluded: investor buys exceeding 33333 euros, investor sells exceeding 4000 contracts and transactions involving an issue that's leverage is not the highest within calls or puts.

\begin{tabular}{lcrrrrrr}
\hline & Obs & Mean & Stdev & p25 & p50 & p75 & p99 \\
\hline & Call contracts & & & & & \\
\hline Value of buys (euros) & 4615 & 1411 & 2831 & 238 & 515 & 1243 & 15627 \\
Value of sells (euros) & 3427 & 1749 & 3406 & 258 & 604 & 1576 & 18469 \\
Leverage of buys & 4615 & 14 & 4.4 & 10 & 12 & 16 & 26 \\
Volume of buys (\# of contracts) & 4615 & 182 & 381 & 30 & 69 & 170 & 2000 \\
Volume of sells (\# of contracts) & 3427 & 216 & 422 & 30 & 80 & 200 & 2400 \\
\hline & Put contracts & & & & & \\
\hline Value of buys (euros) & 5885 & 1611 & 3411 & 211 & 480 & 1295 & 19547 \\
Value of sells (euros) & 4323 & 1837 & 3664 & 258 & 574 & 1638 & 19967 \\
Leverage of buys & 5885 & 14 & 5 & 11 & 14 & 17 & 33 \\
Volume of buys (\# of contracts) & 5885 & 233 & 522 & 30 & 69 & 200 & 2500 \\
Volume of sells (\# of contracts) & 4323 & 244 & 453 & 40 & 90 & 200 & 2300 \\
\hline
\end{tabular}

Table 3: Descriptive statistics, daily data, selected sample. This table shows descriptives for the sample included in Table 2, aggregated at the daily level.

\begin{tabular}{lrrrrrr}
\hline & Obs. & Mean & Stdev & p10 & p50 & p90 \\
\hline$R_{t}^{D A X}$ & 100 & .016 & 1.1 & -1.5 & .039 & 1.4 \\
DLev & 100 & -.2 & .58 & -.92 & -.31 & .56 \\
\hline & Call contracts & & & & \\
\hline Buys (\# of contracts) & 100 & 8400 & 7904 & 1266 & 6072 & 18517 \\
Sells (\# of contracts) & 100 & 7393 & 6198 & 1082 & 5575 & 17450 \\
Buys-Sells (\# of contracts) & 100 & 1007 & 5670 & -4455 & 763 & 6118 \\
Buys (\# of transactions) & 100 & 46 & 34 & 13 & 38 & 103 \\
Sells (\# of transactions) & 100 & 34 & 22 & 10 & 29 & 68 \\
Buys-Sells (\# of transactions) & 100 & 12 & 27 & -18 & 8 & 50 \\
\hline & Put contracts & & & & \\
\hline Buys (\# of contracts) & 100 & 13685 & 10116 & 3927 & 10516 & 25893 \\
Sells (\# of contracts) & 100 & 10560 & 8908 & 2111 & 7423 & 24837 \\
Buys-Sells (\# of contracts) & 100 & 3125 & 10070 & -7758 & 2678 & 14292 \\
Buys (\# of transactions) & 100 & 59 & 27 & 26 & 55 & 93 \\
Sells (\# of transactions) & 100 & 43 & 27 & 17 & 34 & 81 \\
Buys-Sells (\# of transactions) & 100 & 16 & 36 & -26 & 13 & 58 \\
\hline
\end{tabular}


Table 4: Benchmark results. Buys $s_{i, t}\left(\operatorname{Sell}_{i, t}\right)$ is the total number of contracts bought (sold) during day $t$ by investors of issue $i . R_{t-1}^{D A X}$ is the log return of the DAX index from the close of $t-2$ to the close of $t-1$ times 100. Put is an indicator for the issue being a put (and is also included separately in all specifications but omitted from the tables) and $D L e v_{t-1}$ is the difference between the (log) leverages of the highest levered call and put at the closing time of the previous trading day. A set of controls known at $t-1$ including the total number of outstanding contracts of issue $i$ (only known by the bank), days since issuance and days to maturity are included in $X_{i, t-1}$. We report p-values from $\mathrm{F}$-tests for the joint significance of $R_{t-1}^{D A X} / P U T_{i} \times R_{t-1}^{D A X}$ and of $\underline{D L e v_{t-1} / P U T_{i} \times D L e v_{t-1} \text {, respectively. }}$

\begin{tabular}{|c|c|c|c|c|c|}
\hline VARIABLES & $\begin{array}{c}1) \\
\text { Buys }_{i t}- \\
\text { Sells }_{i t}\end{array}$ & $\begin{array}{c}(2) \\
\text { Buys }_{i t}- \\
\text { Sells }_{i t}\end{array}$ & $\begin{array}{c}(3) \\
\text { Buys }_{i t}- \\
\text { Sells }_{i t}\end{array}$ & Buys $_{i t}$ & Sells $s_{i t}$ \\
\hline$R_{t-1}^{D A X}$ & $\begin{array}{c}-1,829^{* * *} \\
(458.0)\end{array}$ & $\begin{array}{c}-1,372^{* *} \\
(598.0)\end{array}$ & $\begin{array}{c}-1,026^{* * *} \\
(177.9)\end{array}$ & $\begin{array}{l}-347.2 \\
(310.0)\end{array}$ & $\begin{array}{c}678.5^{* *} \\
(241.5)\end{array}$ \\
\hline$P U T_{i} \times R_{t-1}^{D A X}$ & $\begin{array}{c}3,660^{* * *} \\
(916.9)\end{array}$ & $\begin{array}{c}2,466^{* *} \\
(977.5)\end{array}$ & $\begin{array}{c}2,118^{* *} \\
(776.9)\end{array}$ & $\begin{array}{l}-515.6 \\
(902.3)\end{array}$ & $\begin{array}{c}-2,634^{* * *} \\
(352.6)\end{array}$ \\
\hline$D L e v_{t-1}$ & & $\begin{array}{c}3,639^{* *} \\
(1,624)\end{array}$ & $\begin{array}{c}4,857^{* * *} \\
(981.5)\end{array}$ & $\begin{array}{c}9,958^{* * *} \\
(1,249)\end{array}$ & $\begin{array}{c}5,102^{* *} \\
(1,379)\end{array}$ \\
\hline$P U T_{i} \times D L e v_{t-1}$ & & $\begin{array}{c}-9,630^{* * *} \\
(3,442)\end{array}$ & $\begin{array}{c}-12,010^{* * *} \\
(2,766)\end{array}$ & $\begin{array}{c}-14,461^{* * *} \\
(2,600)\end{array}$ & $\begin{array}{l}-2,451 \\
(1,965)\end{array}$ \\
\hline Observations & 196 & 196 & 196 & 196 & 196 \\
\hline R-squared & 0.070 & 0.183 & 0.142 & 0.209 & 0.250 \\
\hline Controls & No & Yes & Yes & Yes & Yes \\
\hline Issue FE & No & No & Yes & Yes & Yes \\
\hline $\mathrm{F}$-test $\beta_{1}=\beta_{2}=0(\mathrm{p}$-val $)$ & 0.000 & 0.030 & 0.003 & 0.179 & 0.000 \\
\hline F-test $\gamma_{1}=\gamma_{2}=0(\mathrm{p}$-val $)$ & & 0.021 & 0.007 & 0.000 & 0.015 \\
\hline
\end{tabular}

Robust standard errors in parentheses

*** $\mathrm{p}<0.01,{ }^{* *} \mathrm{p}<0.05, * \mathrm{p}<0.1$ 
Table 5: Results: large trades. Buys $s_{i, t}^{l}\left(\right.$ Sell $\left._{i, t}^{l}\right)$ is the total number of contracts bought (sold) during day $t$ by investors of issue $i$ using transactions involving over 200 contracts. See Table 4 for other variables' definitions.

\begin{tabular}{|c|c|c|c|c|c|}
\hline VARIABLES & $\begin{array}{c}(1) \\
\text { Buys } s_{i t}^{l}- \\
\text { Sells } s_{i t}^{l}\end{array}$ & $\begin{array}{c}(2) \\
\text { Buys }_{i t}^{l}- \\
\text { Sells } \\
\text { it }\end{array}$ & $\begin{array}{c}(3) \\
\text { Buys } s_{i t}^{l}- \\
\text { Sells } s_{i t}^{l}\end{array}$ & $\begin{array}{c}\text { (4) } \\
\text { Buyssit }\end{array}$ & $\begin{array}{c}(5) \\
\text { Sells } \\
\text { it }\end{array}$ \\
\hline$R_{t-1}^{D A X}$ & $\begin{array}{c}-1,371^{* * *} \\
(365.0)\end{array}$ & $\begin{array}{c}-1,035^{* *} \\
(484.7)\end{array}$ & $\begin{array}{c}-745.5^{* *} \\
(222.5)\end{array}$ & $\begin{array}{l}-151.3 \\
(355.4)\end{array}$ & $\begin{array}{c}594.3^{* *} \\
(236.5)\end{array}$ \\
\hline$P U T_{i} \times R_{t-1}^{D A X}$ & $\begin{array}{c}2,764^{* * *} \\
(751.3)\end{array}$ & $\begin{array}{c}1,664^{* *} \\
(803.0)\end{array}$ & $\begin{array}{l}1,372^{*} \\
(684.7)\end{array}$ & $\begin{array}{l}-772.0 \\
(874.0)\end{array}$ & $\begin{array}{c}-2,144^{* * *} \\
(360.1)\end{array}$ \\
\hline$D L e v_{t-1}$ & & $\begin{array}{c}2,765^{* *} \\
(1,396)\end{array}$ & $\begin{array}{c}3,733^{* * *} \\
(984.2)\end{array}$ & $\begin{array}{c}7,765^{* * *} \\
(920.5)\end{array}$ & $\begin{array}{c}4,032^{* *} \\
(1,257)\end{array}$ \\
\hline$P U T_{i} \times D L e v_{t-1}$ & & $\begin{array}{c}-8,578^{* * *} \\
(3,020)\end{array}$ & $\begin{array}{c}-10,527^{* * *} \\
(2,328)\end{array}$ & $\begin{array}{c}-11,951^{* * *} \\
(2,252)\end{array}$ & $\begin{array}{l}-1,423 \\
(1,836)\end{array}$ \\
\hline Observations & 196 & 196 & 196 & 196 & 196 \\
\hline R-squared & 0.064 & 0.180 & 0.130 & 0.183 & 0.220 \\
\hline Controls & No & Yes & Yes & Yes & Yes \\
\hline Issue FE & No & No & Yes & Yes & Yes \\
\hline F-test $\beta_{1}=\beta_{2}=0(p$-val $)$ & 0.000 & 0.070 & 0.041 & 0.286 & 0.002 \\
\hline F-test $\gamma_{1}=\gamma_{2}=0(\mathrm{p}$-val $)$ & & 0.018 & 0.011 & 0.000 & 0.016 \\
\hline
\end{tabular}

Robust standard errors in parentheses

*** $\mathrm{p}<0.01,{ }^{* *} \mathrm{p}<0.05, * \mathrm{p}<0.1$

Table 6: Results: small trades. Buys $s_{i, t}^{s}\left(\right.$ Sell $\left._{i, t}^{s}\right)$ is the total number of contracts bought (sold) during day $t$ by investors of issue $i$ using transactions involving at most 200 contracts. See Table 4 for other variables' definitions.

\begin{tabular}{|c|c|c|c|c|c|}
\hline VARIABLES & $\begin{array}{c}\text { (1) } \\
\text { Buys sit } \\
\text { Sells } s_{i t}^{s}\end{array}$ & $\begin{array}{c}(2) \\
B u y s_{i t}^{s}- \\
\text { Sells } s_{i t}^{s}\end{array}$ & $\begin{array}{c}(3) \\
\text { Buys } s_{i t}^{s}- \\
\text { Sells } s_{i t}^{s}\end{array}$ & Buys $s_{i t}^{s}$ & Sells sit \\
\hline$R_{t-1}^{D A X}$ & $\begin{array}{c}-458.4^{* * *} \\
(143.8)\end{array}$ & $\begin{array}{c}-336.9^{* *} \\
(160.5)\end{array}$ & $\begin{array}{c}-280.2^{* *} \\
(83.84)\end{array}$ & $\begin{array}{c}-195.9^{* *} \\
(61.84)\end{array}$ & $\begin{array}{c}84.27^{* *} \\
(31.70)\end{array}$ \\
\hline$P U T_{i} \times R_{t-1}^{D A X}$ & $\begin{array}{c}895.0^{* * * *} \\
(234.0)\end{array}$ & $\begin{array}{c}802.0^{* * * *} \\
(244.9)\end{array}$ & $\begin{array}{c}746.1^{* * *} \\
(145.4)\end{array}$ & $\begin{array}{c}256.5^{* *} \\
(100.4)\end{array}$ & $\begin{array}{c}-489.6^{\text {*** }} \\
(52.04)\end{array}$ \\
\hline$D L e v_{t-1}$ & & $\begin{array}{c}874.3^{* *} \\
(380.3)\end{array}$ & $\begin{array}{c}1,124^{* *} \\
(342.2)\end{array}$ & $\begin{array}{c}2,193^{* * *} \\
(498.1)\end{array}$ & $\begin{array}{c}1,070^{* * *} \\
(237.8)\end{array}$ \\
\hline$P U T_{i} \times D L e v_{t-1}$ & & $\begin{array}{c}-1,052^{*} \\
(595.0)\end{array}$ & $\begin{array}{c}-1,482^{*} \\
(672.8)\end{array}$ & $\begin{array}{c}-2,510^{* * *} \\
(675.4)\end{array}$ & $\begin{array}{c}-1,027^{* *} \\
(368.8)\end{array}$ \\
\hline Observations & 196 & 196 & 196 & 196 & 196 \\
\hline R-squared & 0.065 & 0.170 & 0.157 & 0.239 & 0.306 \\
\hline Controls & No & Yes & Yes & Yes & Yes \\
\hline Issue FE & No & No & Yes & Yes & Yes \\
\hline $\mathrm{F}$-test $\beta_{1}=\beta_{2}=0(\mathrm{p}$-val $)$ & 0.001 & 0.005 & 0.006 & 0.051 & 0.000 \\
\hline F-test $\gamma_{1}=\gamma_{2}=0(p$-val $)$ & & 0.073 & 0.045 & 0.012 & 0.010 \\
\hline
\end{tabular}

Robust standard errors in parentheses *** $\mathrm{p}<0.01,{ }^{* *} \mathrm{p}<0.05,{ }^{*} \mathrm{p}<0.1$ 
Table 7: Results: transactions. This table reports the results for transactions. Buys $s_{i, t}^{t r}$ $\left(\right.$ Sell $\left._{i, t}^{t r}\right)$ is the total number of transactions during day $t$ through which investors purchase (sell) any number of contracts of issue $i$. All transactions are considered for the highest levered call and highest levered put. See Table 4 for other variables' definitions.

\begin{tabular}{|c|c|c|c|c|c|}
\hline VARIABLES & $\begin{array}{c}(1) \\
\text { Buys } s_{i t}^{t r}- \\
\text { Sells } s_{i t}^{t r} \\
\end{array}$ & $\begin{array}{c}(2) \\
\text { Buys } s_{i t}^{t r}- \\
\text { Sells } s_{i t}^{t r}\end{array}$ & $\begin{array}{c}(3) \\
\text { Buys } s_{i t}^{t r}- \\
\text { Sells } s_{i t}^{t r} \\
\end{array}$ & $\begin{array}{c}\text { (4) } \\
\text { Buys }_{i t}^{\text {tr }} \\
\end{array}$ & Sells $s_{i t}^{t r}$ \\
\hline$R_{t-1}^{D A X}$ & $\begin{array}{c}-8.369^{* * *} \\
(2.408)\end{array}$ & $\begin{array}{c}-6.732^{* *} \\
(2.666)\end{array}$ & $\begin{array}{c}-5.711^{* * *} \\
(1.361)\end{array}$ & $\begin{array}{c}-4.343^{* * *} \\
(1.042)\end{array}$ & $\begin{array}{l}1.368^{*} \\
(0.585)\end{array}$ \\
\hline$P U T_{i} \times R_{t-1}^{D A X}$ & $\begin{array}{c}17.66^{* * *} \\
(4.186)\end{array}$ & $\begin{array}{c}16.36^{* * *} \\
(4.374)\end{array}$ & $\begin{array}{c}15.68^{* * *} \\
(2.515)\end{array}$ & $\begin{array}{c}6.274^{* * *} \\
(1.417)\end{array}$ & $\begin{array}{c}-9.406^{* * *} \\
(1.321)\end{array}$ \\
\hline$D L e v_{t-1}$ & & $\begin{array}{c}12.18^{* *} \\
(5.993)\end{array}$ & $\begin{array}{c}16.01^{* *} \\
(4.584)\end{array}$ & $\begin{array}{c}33.49^{* * *} \\
(6.688)\end{array}$ & $\begin{array}{c}17.48^{* * *} \\
(3.702)\end{array}$ \\
\hline$P U T_{i} \times D L e v_{t-1}$ & & $\begin{array}{l}-15.34 \\
(9.948)\end{array}$ & $\begin{array}{l}-19.98^{*} \\
(8.356)\end{array}$ & $\begin{array}{c}-36.25^{* * *} \\
(8.013)\end{array}$ & $\begin{array}{c}-16.27^{* *} \\
(6.258)\end{array}$ \\
\hline Observations & 196 & 196 & 196 & 196 & 196 \\
\hline R-squared & 0.089 & 0.179 & 0.172 & 0.224 & 0.274 \\
\hline Controls & No & Yes & Yes & Yes & Yes \\
\hline Issue FE & No & No & Yes & Yes & Yes \\
\hline $\mathrm{F}$-test $\beta_{1}=\beta_{2}=0(\mathrm{p}$-val $)$ & 0.000 & 0.001 & 0.002 & 0.010 & 0.001 \\
\hline F-test $\gamma_{1}=\gamma_{2}=0(p-v a l)$ & & 0.129 & 0.036 & 0.007 & 0.007 \\
\hline
\end{tabular}

Robust standard errors in parentheses $* * * \mathrm{p}<0.01,{ }^{* *} \mathrm{p}<0.05, * \mathrm{p}<0.1$

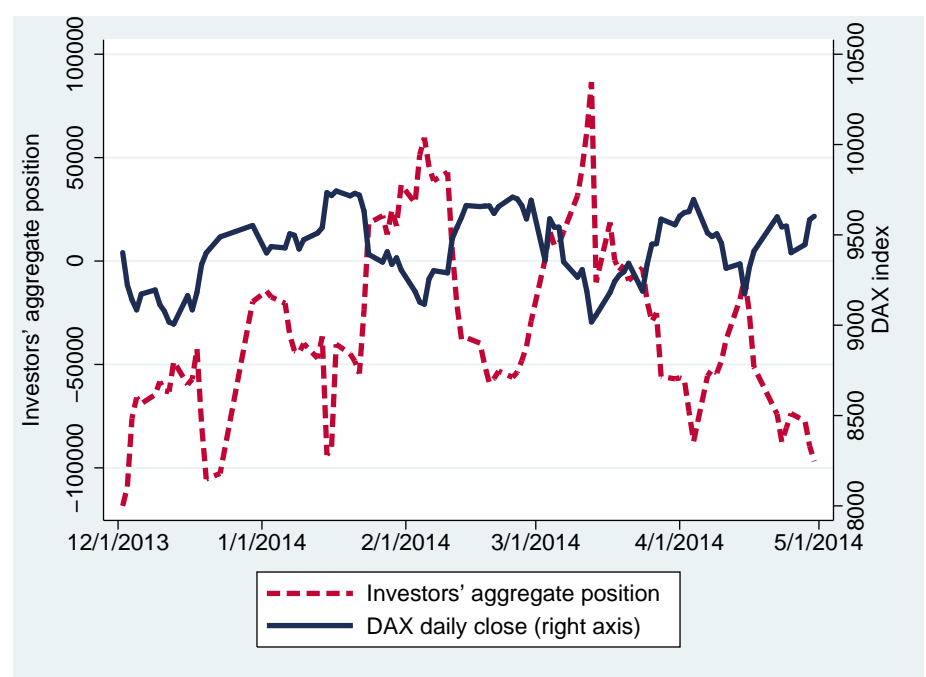

Figure 1: The evolution of the DAX index (solid line, right axis) and investors' aggregate position. Investors' aggregate position is the difference between the total number of call contracts and put contracts investors hold at the end of the day. 


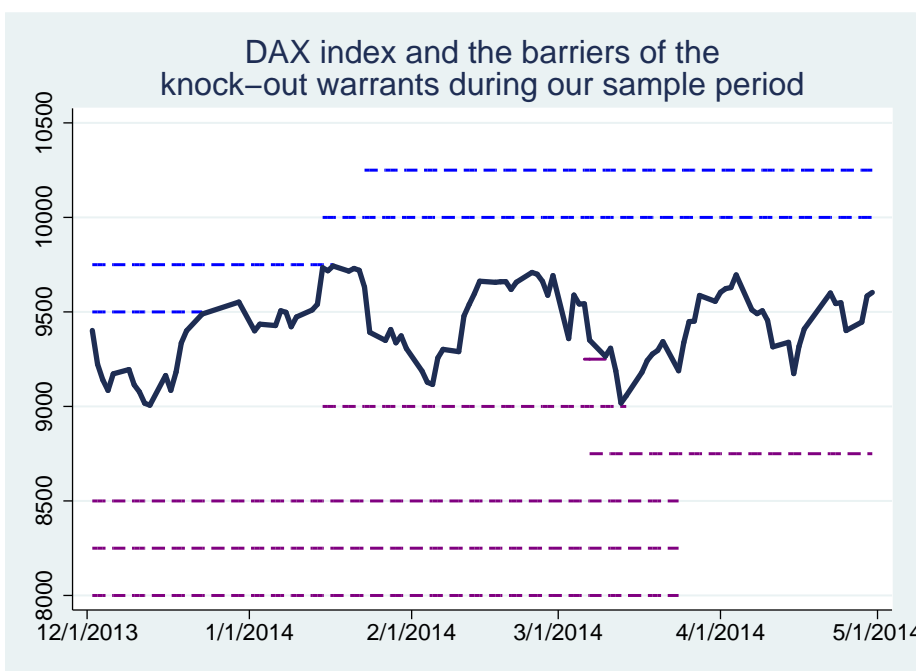

Figure 2: DAX index and offered knock-out warrants during our sample. Dashed horizontal segments indicate the lifespan of knock-out put contracts represented by their barriers. Solid horizontal segments indicate the lifespan of knock-out call contracts represented by their barriers. After introduction, warrants either get knocked-out (4 cases) or expire at maturity (3 cases). In three cases the products only expired after our sample period ended.

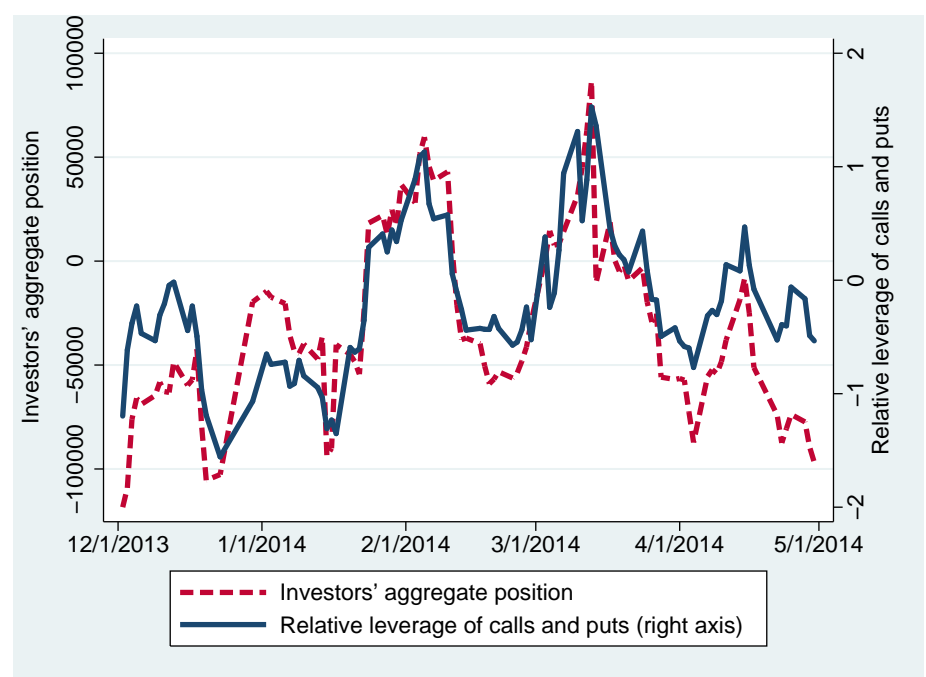

Figure 3: Relative leverage of offered call and put warrants and investors' aggregate position. Relative leverage (solid line, right axis) is defined as the difference between the Log leverage of the highest levered call and the Log leverage of the highest levered put, where leverage is the absolute percent change in the warrants value if the underlying changes by one percent. Investors' aggregate position (dashed line) is the difference between the total number of call contracts and put contracts investors hold at the end of the day. 


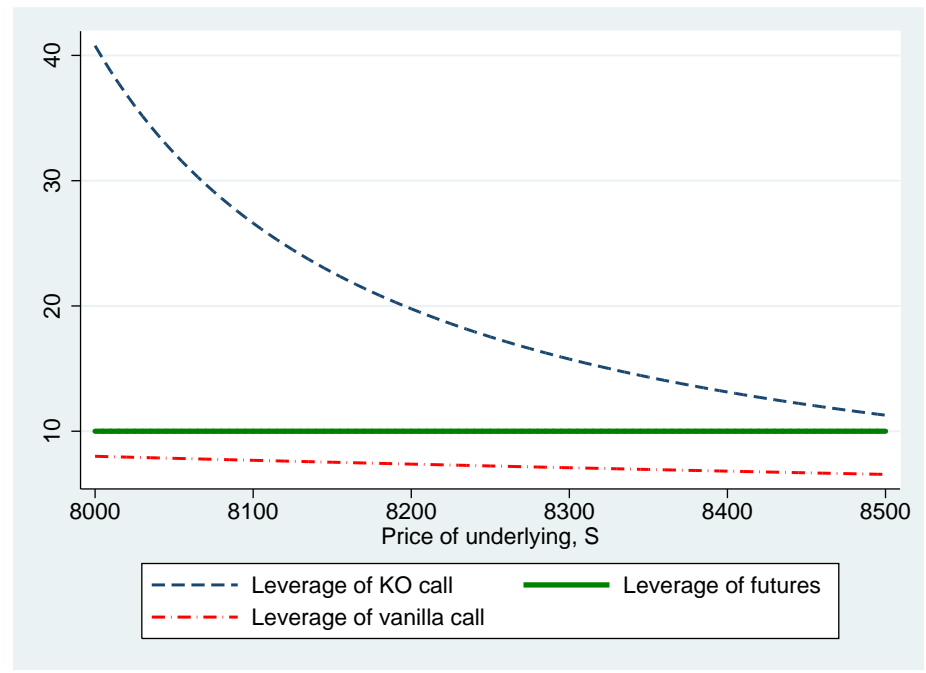

Figure 4: Leverage of a $\mathrm{KO}$ call, a vanilla call and a futures contract as a function of the underlying's price. Leverage is defined as an elasticity of the derivative's value with respect to the underlying's price. Note that option leverages were numerically approximated based on the Black-Scholes model. Parameters used are provided in Table 8. For the leverage of the futures, we have assumed a margin of $10 \%$.

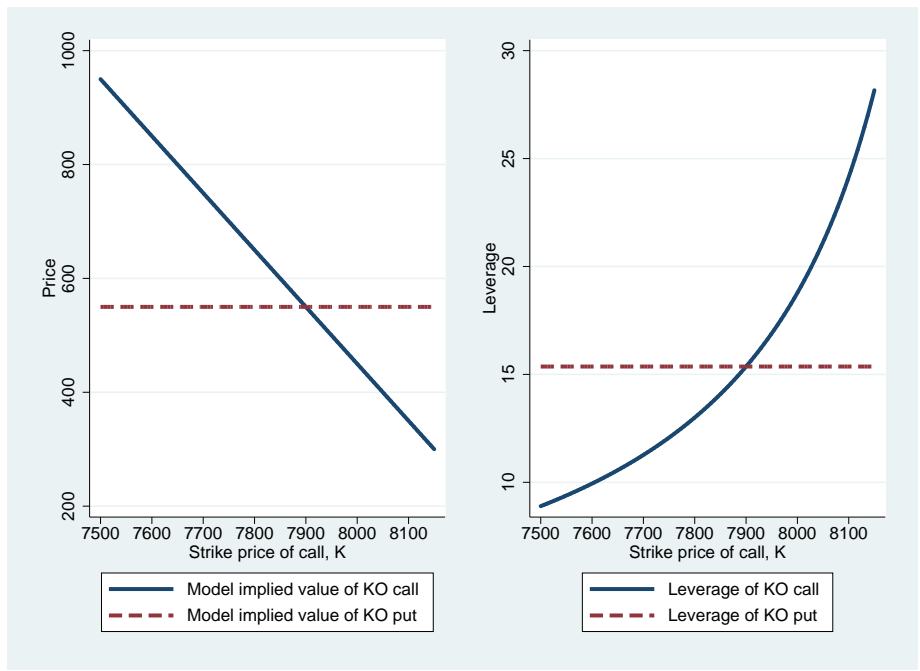

Figure 5: Value and leverage of a $\mathrm{KO}$ call and a $\mathrm{KO}$ put as a function of the strike price of the offered $\mathrm{KO}$ call. Parameters for the KO put are $K=9000, B=8750$, while for the $\mathrm{KO}$ call the barrier is always set to $B=K+250$. Parameters common to both products are $S=8450, r_{f}=0, T=1, \sigma=0.2$. Model implied values are based on Black-Scholes assumptions. 


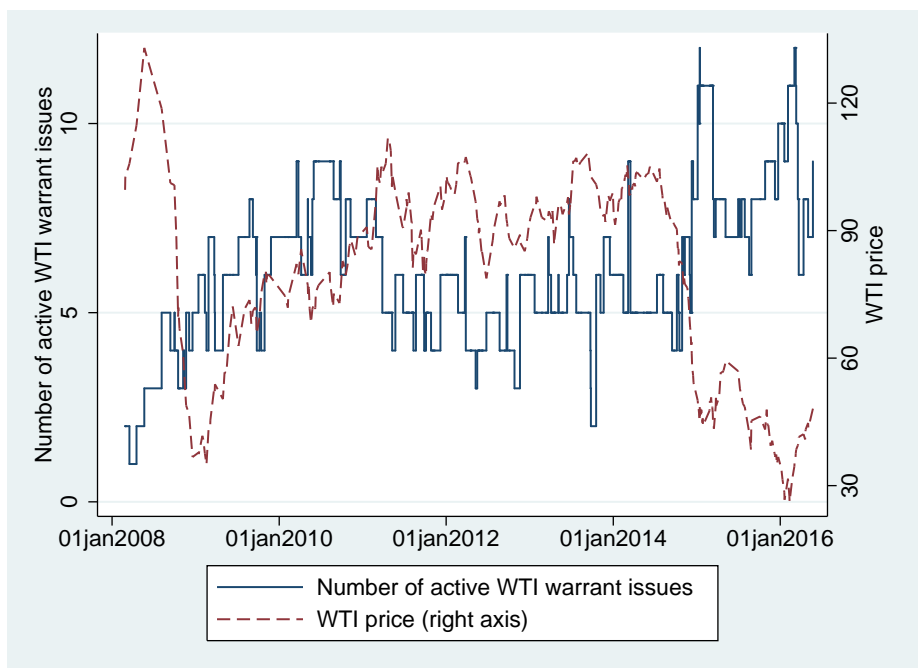

Figure 6: Example of product issuance. This figure shows the number of active warrant issues, that have the WTI Oil price as their underlying, together with the evolution of the underlying's price (right axis).

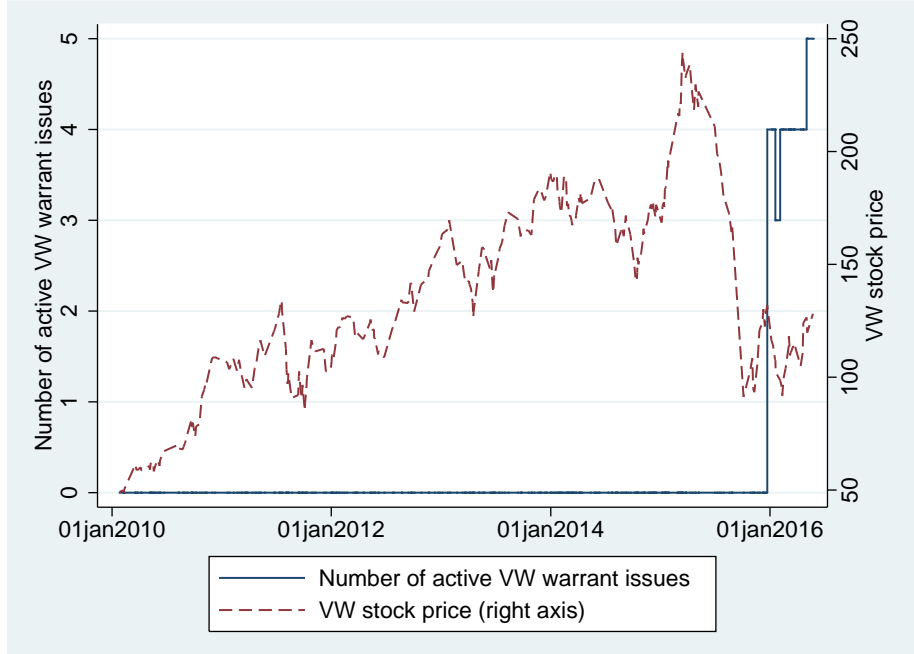

Figure 7: Example of product issuance. This figure shows the number of active warrant issues, that have the Volkswagen stock price as their underlying, together with the evolution of the underlying's price (right axis). 


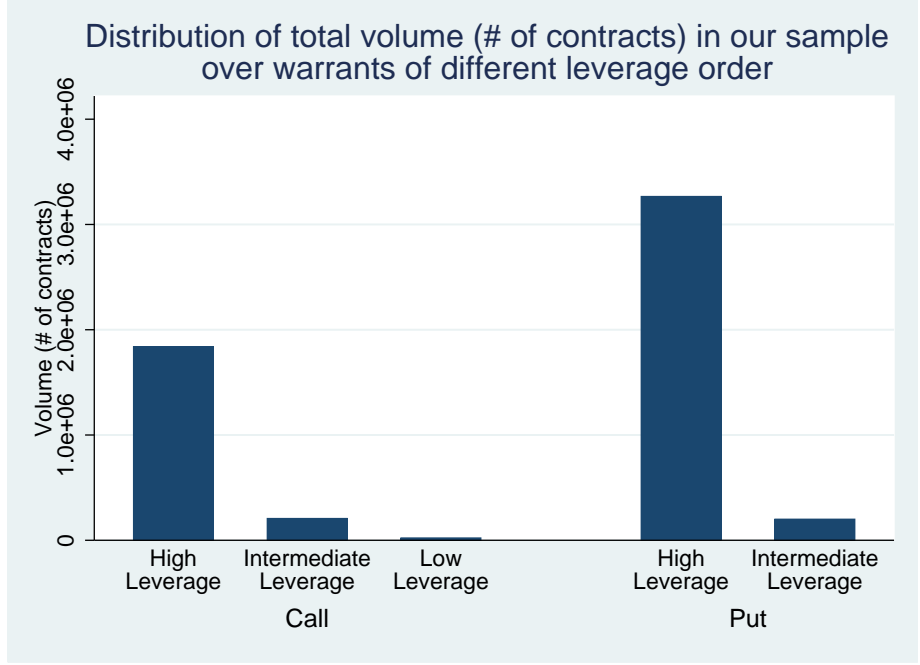

Figure 8: Total volume (\# of contracts) by leverage order. This chart shows the total volume in our sample, separately for calls and puts, over the leverage order of available warrants. Note that only those trading days were considered when at least two different calls and puts were available.

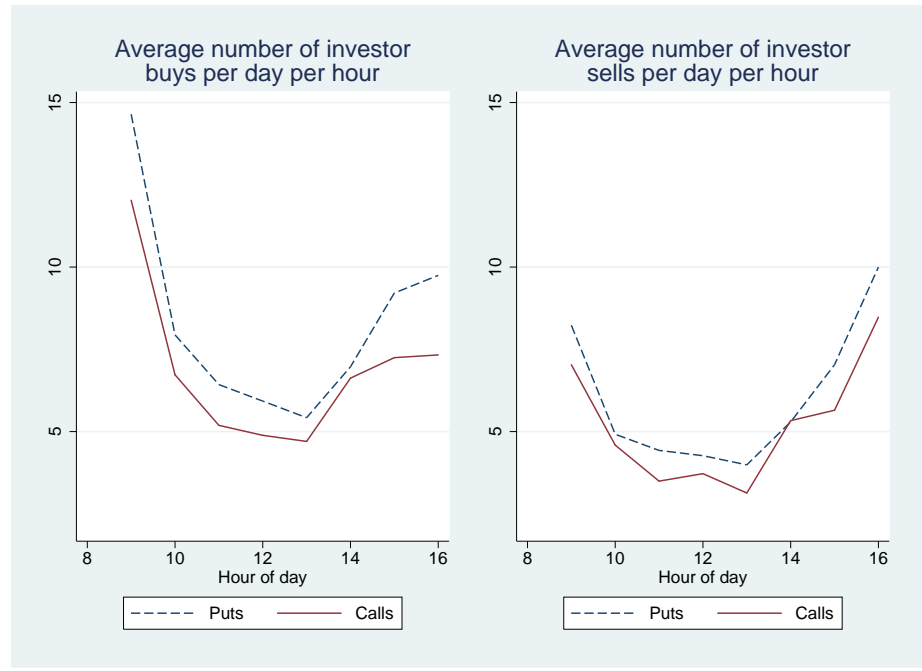

Figure 9: Investors' trading activity within trading hours. This graph shows the average number of buy transactions and resell transactions investors carry out with the bank. 


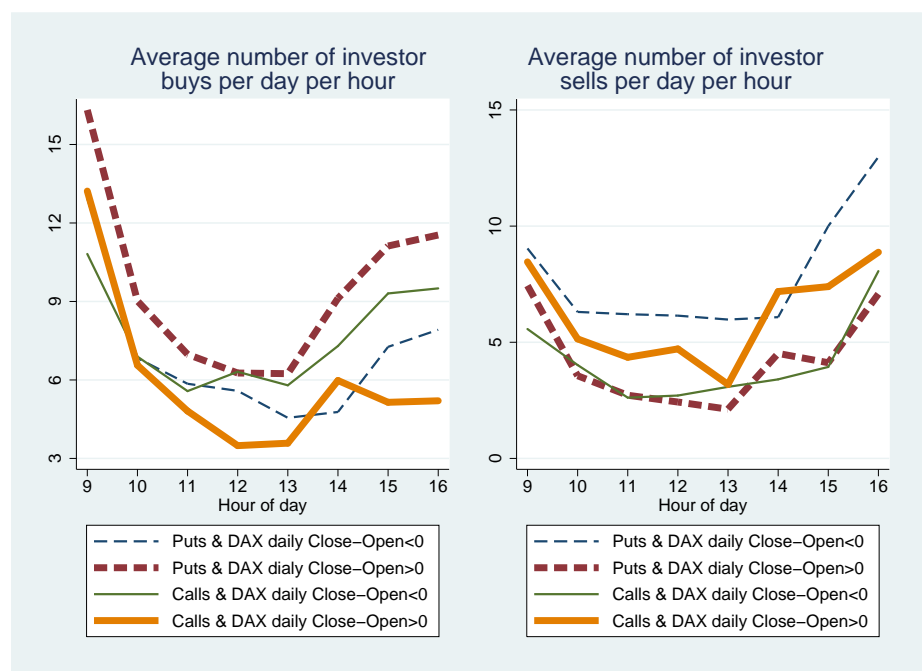

Figure 10: Investors' trading activity within trading hours by within day market movement. This graph shows the average number of buy and resell transactions by the hour of day, computed separately for days when the DAX index increased during the day (Close-Open $>0$ ) and decreased during the day (Close-Open $<0$ ). Solid (dashed) lines correspond to calls (puts) while thick (thin) lines correspond to days when the DAX increased (decreased) within the day.

\section{The Delta and Vega of a KO call}

In order to build some intuition for the pricing of KO products, it is useful to compare the behavior of their model implied prices to futures prices and to European vanilla option prices. These comparisons are useful because banks market these products by advertising that they have similar characteristics to futures, except that once the barrier is hit, their positions are automatically closed, so the investors do not have to hold a margin account. Also, by comparing to vanilla options, the effects of path dependence will become clear.

Consider a $\mathrm{KO}$ call. The following table summarizes the benchmark parameters for the contract used in this example. The underlying price is assumed to evolve consistent with Black-Scholes assumptions, implying that it can be characterized by the risk-free interest rate $\left(r_{f}\right)$ and the volatility of returns $(\sigma)$ under the risk-neutral measure:

\begin{tabular}{|l|c|}
\hline Parameter & Value \\
\hline Strike price, $K$ & 7750 \\
Barrier, $B$ & 8000 \\
Underlying's price, $S(0)$ & 8250 \\
Maturity in years, $T$ & 0.5 \\
Risk free interest rate, $r_{f}$ & 0.05 \\
Volatility of the underlying, $\sigma$ & 0.2 \\
\hline
\end{tabular}

Table 8: Benchmark product characteristics for a KO call. The parameter values above will be used to illustrate the characteristics of $\mathrm{KO}$ warrants.

Figures 1 6 summarize the results. Using the Black-Scholes model, one can find a closed form solution for the price of the KO call, assuming that the residual value in 
case of a knock-out event is the difference between the barrier and the strike price.$^{23}{ }^{24}$

Figures 1. 3 show the $\Delta$ (absolute price increase of given product if the price of the underlying increases by 1 unit) of the $\mathrm{KO}$ call, a vanilla call and a futures contract. The futures contract always has a $\Delta=\left(1+r_{f}\right)^{T}$ and it is well known that the vanilla call always has a $\Delta<1$. Compared to these, the $\mathrm{KO}$ call has a larger $\Delta$, implying that it is not identical to a futures contract. Observe on Figure 1 that $\Delta$ converges to 1 for both options as they become heavily in the money. Figure 3 highlights the effect of volatility on $\Delta$. Contrary to a vanilla call, the KO call has a more stable $\Delta$, implying that it is more useful for directional bets than a vanilla call.

Figures 4,6 show the Vega (percent change in asset's value if volatility increases by $1 \%$ point) of the three products. Naturally, the futures always has a Vega equal to zero. Interestingly, the KO call has a negative Vega, implying that the $\mathrm{KO}$ call's value is decreasing in volatility. This is in sharp contrast with the properties of a vanilla call and highlight the important affect the barrier plays. Higher volatility increases the probability of a knock-out event resulting in the lowest possible payoff. Observe, that as volatility increases, the Vega of the $\mathrm{KO}$ call will converge to zero as the knock-out event becomes a certainty (Figure 6).

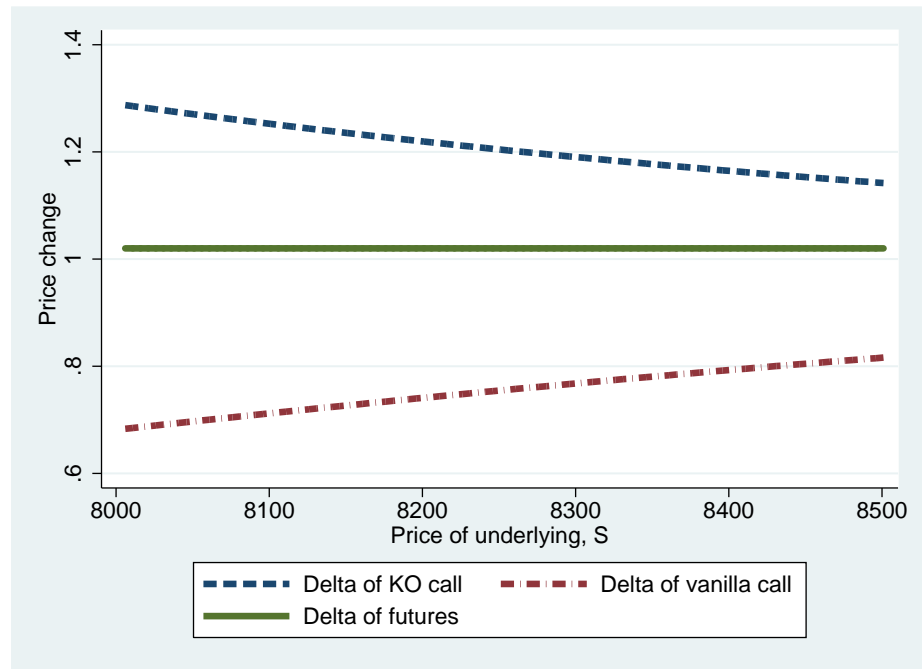

Figure 1: This figure shows the $\Delta$ of a $\mathrm{KO}$ call, a vanilla call and a futures contract as a function of the underlying's price. The $\Delta$ is the absolute change in the price of the derivative when the underlying's price changes by one unit. Parameters used are provided in Table 8 .

\footnotetext{
${ }^{23}$ Rubinstein and Reiner $\sqrt{1991)}$ were the first to provide a closed form solution for the value of barrier options under the Black-Scholes assumptions.

${ }^{24}$ With this assumption the residual value can me modelled as an American style binary put option, which has a closed form solution in the Black-Scholes world.
} 


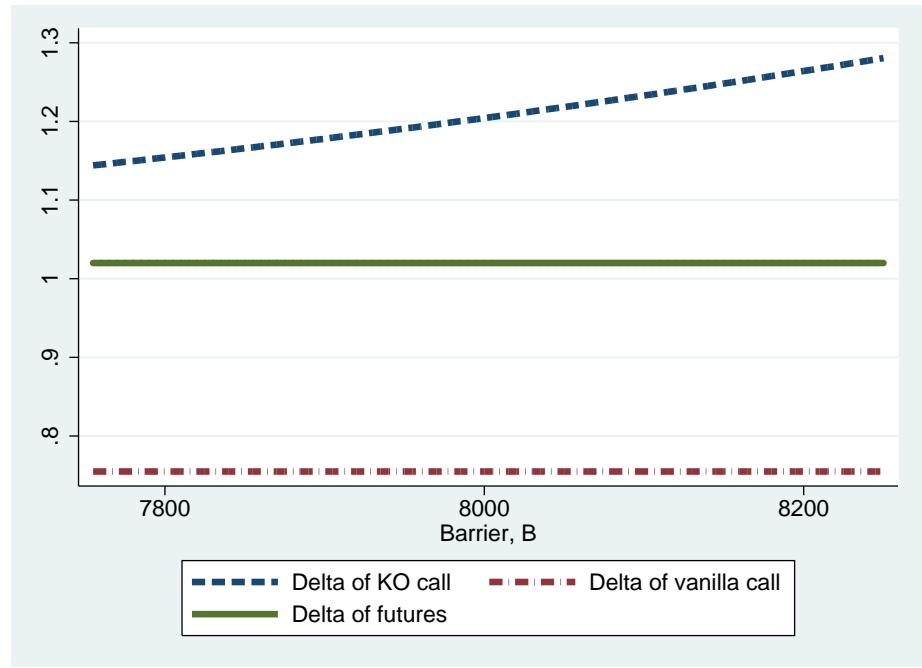

Figure 2: This figure shows the $\Delta$ of a $\mathrm{KO}$ call, a vanilla call and a futures contract as a function of the barrier. The $\Delta$ is the absolute change in the price of the derivative when the underlying's price changes by one unit. Parameters used are provided in Table 8 .

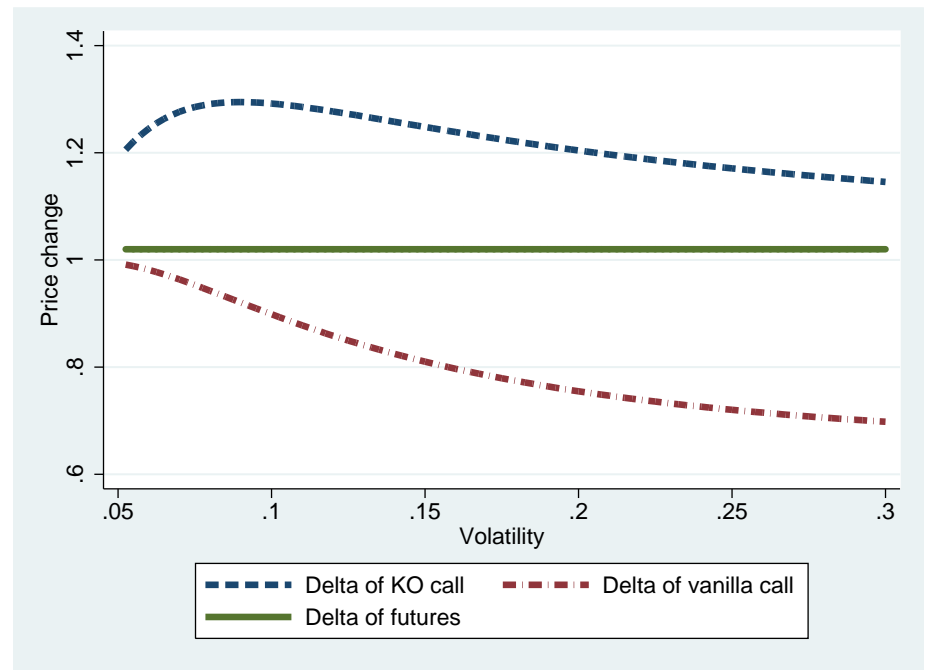

Figure 3: This figure shows the $\Delta$ of a KO call, a vanilla call and a futures contract as a function of the underlying's volatility. The $\Delta$ is the absolute change in the price of the derivative when the underlying's price changes by one unit. Parameters used are provided in Table 8 . 


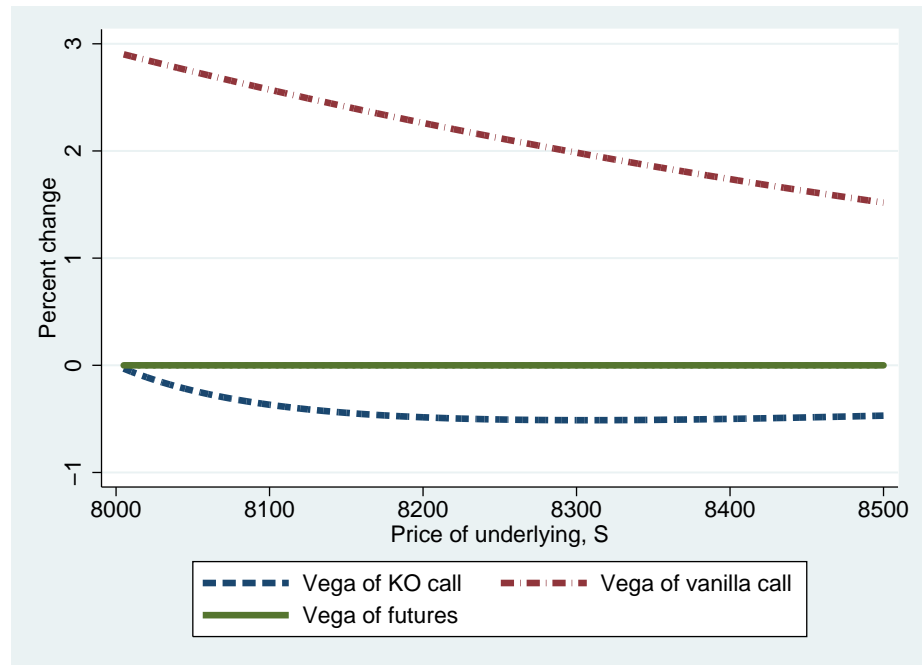

Figure 4: This figure shows the Vega of a KO call, a vanilla call and a futures contract as a function of the underlying's price. The Vega is the percent change in the price of the derivative when the underlying's volatility increases by $1 \%$ point. Parameters used are provided in Table 8 .

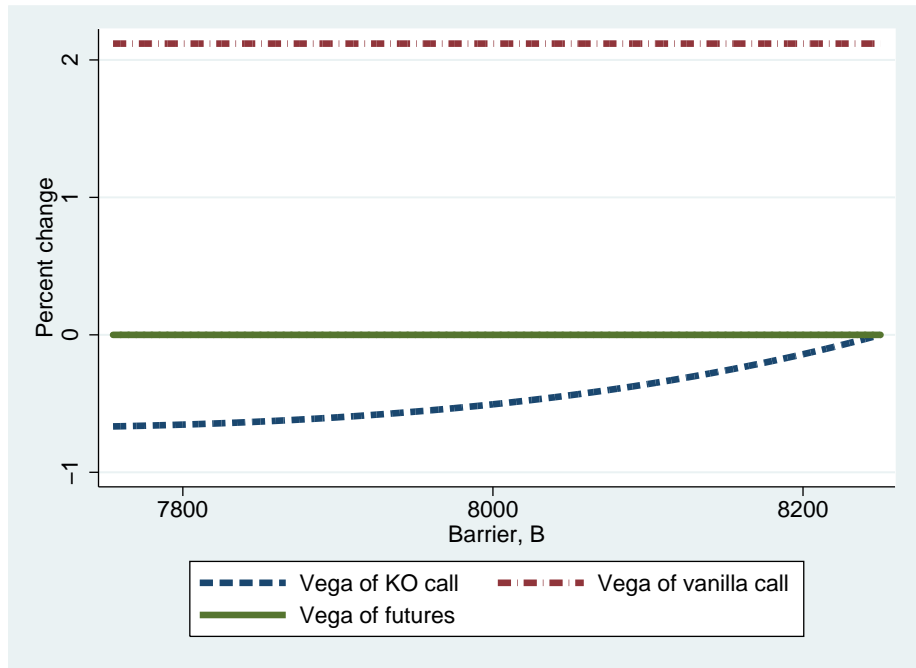

Figure 5: This figure shows the Vega of a KO call, a vanilla call and a futures contract as a function of the barrier. The Vega is the percent change in the price of the derivative when the underlying's volatility increases by $1 \%$ point. Parameters used are provided in Table 8. 


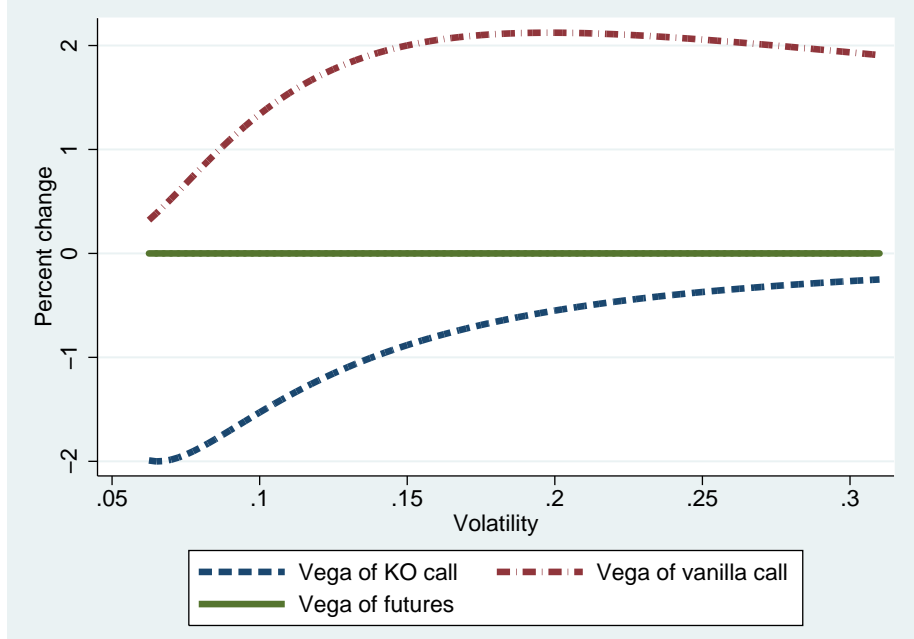

Figure 6: This figure shows the Vega of a KO call, a vanilla call and a futures contract as a function of the underlying's volatility. The Vega is the percent change in the price of the derivative when the underlying's volatility increases by $1 \%$ point. Parameters used are provided in Table 8. 